\title{
Combinatorial Expression of Grp and Neurod6 Defines Dopamine Neuron Populations with Distinct Projection Patterns and Disease Vulnerability
}

\author{
Daniel J. Kramer, ${ }^{1}$-DDavide Risso, ${ }^{3}$ Polina Kosillo, ${ }^{1}$ John Ngai, ${ }^{1,2}$ and ${ }^{-}$Helen S. Bateup ${ }^{1,2}$
}

https://doi.org/10.1523/ENEURO.0152-18.2018

${ }^{1}$ Department of Molecular and Cell Biology, University of California, Berkeley, Berkeley, CA 94720, ${ }^{2}$ Helen Wills Neuroscience Institute, University of California, Berkeley, Berkeley, CA 94720, and ${ }^{3}$ Division of Biostatistics and Epidemiology, Department of Healthcare Policy and Research, Weill Cornell Medicine, New York, NY 10065

\begin{abstract}
Midbrain dopamine neurons project to numerous targets throughout the brain to modulate various behaviors and brain states. Within this small population of neurons exists significant heterogeneity based on physiology, circuitry, and disease susceptibility. Recent studies have shown that dopamine neurons can be subdivided based on gene expression; however, the extent to which genetic markers represent functionally relevant dopaminergic subpopulations has not been fully explored. Here we performed single-cell RNA-sequencing of mouse dopamine neurons and validated studies showing that Neurod6 and Grp are selective markers for dopaminergic subpopulations. Using a combination of multiplex fluorescent in situ hybridization, retrograde labeling, and electrophysiology in mice of both sexes, we defined the anatomy, projection targets, physiological properties, and disease vulnerability of dopamine neurons based on Grp and/or Neurod6 expression. We found that the combinatorial expression of Grp and Neurod6 defines dopaminergic subpopulations with unique features. Grp ${ }^{+} / \mathrm{Neurod}^{+}$ dopamine neurons reside in the ventromedial VTA, send projections to the medial shell of the nucleus accumbens, and have noncanonical physiological properties. Grp ${ }^{+}$Neurod6- dopamine neurons are found in the VTA as well as in the ventromedial portion of the SNc, where they project selectively to the dorsomedial striatum. Grp-/ Neurod $6^{+}$dopamine neurons represent a smaller VTA subpopulation, which is preferentially spared in a 6-OHDA model of Parkinson's disease. Together, our work provides detailed characterization of Neurod6 and Grp expression in the midbrain and generates new insights into how these markers define functionally relevant dopaminergic subpopulations.
\end{abstract}

Key words: Dopamine Neurons; Grp; Neurod6; Retrograde Tracing; Single-Cell RNA-Sequencing; VTA; Cellular Heterogeneity

\section{Significance Statement}

Recent single-cell gene profiling studies have uncovered new subpopulations of midbrain dopamine (DA) neurons defined by their specific patterns of gene expression. How these genetically defined cell types map onto known dopaminergic circuits and functionally defined cell types is unknown. This study elucidates the anatomy, circuitry, physiological properties, and disease susceptibility of midbrain DA neuron subpopulations defined by their expression of two genetic markers. This work not only advances our understanding of the dopaminergic system by providing new information about the properties of specific dopamine neuron subpopulations, it also demonstrates that unbiased genetic classification of neurons can reveal functionally relevant cell types. 


\section{Introduction}

Midbrain dopamine (DA) neurons of the substantia nigra pars compacta $(\mathrm{SNc})$ and ventral tegmental area (VTA) make widespread projections throughout the brain and modulate a host of behaviors from motor function to reward learning to cognition (Björklund and Dunnett, 2007). Although they represent only $\sim 0.03 \%$ of neurons in the mouse brain, DA neurons are heterogeneous, as they vary significantly in their circuitry (Lammel et al., 2011; Watabe-Uchida et al., 2012; Beier et al., 2015; Menegas et al., 2015), physiology (Lammel et al., 2008; Lerner et al., 2015), gene expression (Poulin et al., 2014; La Manno et al., 2016), and response to disease (Damier et al., 1999; Di Salvio et al., 2010a; Blesa and Przedborski, 2014; Brichta and Greengard, 2014). VTA DA neurons are particularly diverse, comprising multiple subcircuits that project to different brain regions and have distinct electrophysiological properties according to their projection target (Lammel et al., 2008; Margolis et al., 2008; Morales and Margolis, 2017). Depending on their connectivity, VTA neurons can also mediate opposing behaviors, such as reward and aversion (Lammel et al., 2012), necessitating tools that can parse this functional heterogeneity to allow selective manipulation of specific VTA subpopulations (Poulin et al., 2016; Vogt Weisenhorn et al., 2016). Building on prior studies that identified genetic differences between SNc and VTA neurons (Grimm et al., 2004; Chung et al., 2005; Greene et al., 2005; Di Salvio et al., $2010 b)$, recent single-cell gene profiling studies have uncovered further genetic heterogeneity in the DA system, including several subtypes of VTA neurons (Poulin et al.,

Received April 16, 2018; accepted May 14, 2018; First published May 21, 2018

The authors declare no competing financial interests.

Author contributions: D.J.K., D.R., J.N., and H.S.B. designed research; D.J.K. and P.K. performed research, D.J.K, D.R., and H.S.B. analyzed data; D.J.K. and H.S.B. wrote the paper.

This work was supported by an NIMH Brain Initiative grant and supplement to J.N. (U01MH105979 H.S.B. Co-Investigator). H.S.B. is supported by a fellowship from the Alfred P. Sloan Foundation (FR-2015-65790) and a NARSAD Young Investigator Grant from the Brain \& Behavior Research Foundation (25073).

Acknowledgments: We thank Dr. David Stafford for his generous guidance with the single-cell RNA-sequencing experiments and Allon Wagner for his work on developing the bioinformatics pipeline. We thank Dr. Diya Das for her assistance with the GEO submission. We thank Ifechukwu Okeke for her assistance with the anatomy experiments and the rest of the Bateup lab for helpful discussions and comments. The NEX-Cre mice were kindly provided by Dr. Klaus-Armin Nave. Imaging experiments were performed in the CRL Molecular Imaging Center, supported by the Gordon and Betty Moore Foundation. We thank Holly Aaron and Jen-Yi for their microscopy training and assistance. Flow cytometry was performed by Hector Nola in the Flow Cytometry Facility, supported by the CRL and CIRM. Single-cell RNA extraction was performed with help from Justin Choi in the Functional Genomics Laboratory and RNA-sequencing was run by Shana McDevitt in the Vincent J. Coates Genome Sequencing Laboratory, supported by Berkeley QB3.

Correspondence should be addressed to: Helen S. Bateup, Dept. of Molecular and Cell Biology, University of California, Berkeley, 142 Life Sciences Addition, Berkeley, CA 94720-3200. Email: bateup@berkeley.edu.

https://doi.org/10.1523/ENEURO.0152-18.2018

Copyright (C) 2018 Kramer et al.

This is an open-access article distributed under the terms of the Creative Commons Attribution 4.0 International license, which permits unrestricted use, distribution and reproduction in any medium provided that the original work is properly attributed.
2014; La Manno et al., 2016). However, it is currently unknown how these genetically defined classes of DA neurons map onto subtypes defined by their circuitry and physiology.

A notable feature of dopaminergic subpopulations is their differential vulnerability to disease. For example, in the neurodegenerative disorder Parkinson's disease (PD), SNc DA neurons degenerate earlier and to a greater degree than VTA DA neurons (Damier et al., 1999; Alberico et al., 2015). The reason for this selective vulnerability is not well understood, although current hypotheses point to differences in the expression of ion channels and metabolic proteins between SNc and VTA neurons (Chung et al., 2005; Greene et al., 2005; Liss et al., 2005; Chan et al., 2007; Brichta and Greengard, 2014; Liu et al., 2014). Despite the relative sparing of the VTA compared to the SNc, $40 \%-77 \%$ of VTA DA neurons still degenerate (AIberico et al., 2015) and the molecular features that define susceptible versus spared VTA neurons are unknown.

Here our goal was to define dopaminergic subpopulations based on gene expression and determine how these populations map onto DA subtypes defined by physiology and circuitry. To do this, we analyzed DA neuron populations marked by two genes, Grp and Neurod6, that we identified by single-cell RNA-sequencing (RNA-seq), and which have previously been reported to mark subpopulations of VTA DA neurons (Chung et al., 2005; Greene et al., 2005; Poulin et al., 2014; La Manno et al., 2016; Viereckel et al., 2016; Khan et al., 2017). With a combination of anatomy, retrograde tracing, and physiology, we show that these genes define overlapping yet distinct DA neuron populations. We further demonstrate that the combinatorial expression of these two genes influences susceptibility to degeneration in a 6-OHDA mouse model of PD. Together, our findings further our understanding of dopaminergic cell type diversity and validate genetic approaches for defining functional cell types in the brain.

\section{Materials and Methods}

\section{Mice}

Animal procedures were conducted in accordance with protocols approved by the University of California, Berkeley Institutional Animal Care and Use Committee (IACUC) and Office of Laboratory Animal Care (OLAC).

For single-cell RNA-seq experiments, DAT ${ }^{\text {RES }}$ Cre mice (Bäckman et al., 2006; Jackson Laboratory strain \#006660, RGD_12905031) were crossed and maintained with the Ai9 tdTomato Cre-reporter line (Madisen et al., 2010; Jackson Laboratory strain \#007909). For physiology experiments, NEX-Cre mice were obtained from Dr. KlausArmin Nave (Goebbels et al., 2006) and crossed with the Ai9 mouse line. C57BL/6J mice were used for retrograde bead injections. The ages, sexes, and numbers of mice used are indicated for each experiment in the results and figure legends.

\section{Single-cell RNA-seq}

Postnatal day $(\mathrm{P}) 26$ to 34 male and female DAT ${ }^{\mathrm{IRES}}$ Cre; Ai9 mice were briefly anesthetized with isoflurane and decapitated, and brains were removed and placed in 
ice-cold, oxygenated artificial CSF (ACSF; $\mathrm{NaCl} 125 \mathrm{~mm}$, $\mathrm{NaHCO}_{3} 25 \mathrm{~mm}, \mathrm{NaH}_{2} \mathrm{PO}_{4} 1.25 \mathrm{~mm}, \mathrm{KCl} 2.5 \mathrm{M}, \mathrm{MgCl}_{2} 1$ $\mathrm{mm}, \mathrm{CaCl}_{2} 2 \mathrm{~mm}$, glucose $25 \mathrm{~mm}$ ). The brain was cut coronally into $275-\mu \mathrm{m}$ sections on a vibratome (Leica VT1000 S) in oxygenated ice-cold choline cutting solution (choline chloride $100 \mathrm{~mm}, \mathrm{NaHCO}_{3} 25 \mathrm{~mm}, \mathrm{NaH}_{2} \mathrm{PO}_{4} 1.25$ $\mathrm{mm}, \mathrm{KCl} 2.5 \mathrm{~mm}, \mathrm{MgCl}_{2} 7 \mathrm{~mm}, \mathrm{CaCl}_{2} 0.5 \mathrm{~mm}$, glucose $25 \mathrm{~mm}$, sodium ascorbate $11.6 \mathrm{~mm}$, sodium pyruvate 3.1 $\mathrm{mm}$ ). Midbrain sections were incubated for $15 \mathrm{~min}$ in ACSF at $34^{\circ} \mathrm{C}$. Midbrain (including the hypothalamus) was dissected in ACSF using forceps under a dissection microscope. Midbrain sections were incubated in $10 \mathrm{ml}$ oxygenated papain solution (papain $10 \mathrm{U} / \mathrm{ml}$ (Worthington \#LK003176) in ACSF with $10 \mathrm{~mm}$ HEPES, $10 \mathrm{U} / \mathrm{ml}$ DNase, $2.5 \mathrm{~mm}$ EDTA, $2.5 \mathrm{~mm}$ cysteine, $1 \mathrm{~mm}$ kynurenic acid, and $5 \mathrm{~mm} \mathrm{CaCl}_{2}$ ) for $25 \mathrm{~min}$ at $34^{\circ} \mathrm{C}$. Following papain digestion, tissue was placed into $9 \mathrm{ml}$ oxygenated STOP-ovomucoid inhibitor solution [1 $\mathrm{ml} / \mathrm{mg}$ ovomucoid (Worthington \#LK003182) in HEPES-ACSF, $10 \mathrm{U} / \mathrm{ml}$ DNase, $1 \mathrm{~mm}$ kynurenic acid, and $5 \mathrm{mM} \mathrm{CaCl}_{2}$ ] and bubbled gently at $34^{\circ} \mathrm{C} .8 \mathrm{ml}$ of the supernatant solution was removed, and the tissue was triturated serially in the remaining $2 \mathrm{ml}$ of solution with polished 3-, 2-, and 1-mm glass pipettes to create a single-cell suspension. The $2 \mathrm{ml}$ single-cell suspension was spun down in a $20 \%$ Percoll solution (600 $\mu$ l Percoll (Sigma \#P4937) in $2.4 \mathrm{ml}$ STOP-ovomucoid solution at $430 \times g$ for $6 \mathrm{~min}$ at room temperature (RT). The supernatant was aspirated, leaving $\sim 50 \mu$ l of solution and the cell pellet. The pellet was resuspended in $1 \mathrm{ml}$ HEPES-ACSF with $1 \mathrm{~mm}$ kynurenic acid and 5\% FBS (Life Technologies \#16140063).

This single-cell suspension was sorted on a BD Influx cell sorter in the Flow Cytometry Facility at UC Berkeley. Cells were gated for $\mathrm{PI}$-/tdTomato ${ }^{+}$and sorted into a PCR tube. Based on the number of neurons sorted and cell viability count, neurons were brought to $\sim 200,000$ neurons $/ \mathrm{ml}$. Neurons were then put into a large Fluidigm C1 chip, and each of the 96 wells was visually inspected to verify cell presence, cell health, and tdTomato expression. Wells containing cell doublets were excluded from further processing.

Cells went through single-cell mRNA extraction using the Fluidigm $\mathrm{C} 1$ system in the Functional Genomics Laboratory at UC Berkeley. Single-cell cDNA was removed and measured via Qubit. Any cell that gave $<0.3 \mu \mathrm{g} / \mathrm{ml}$ of cDNA was removed due to likely low quality. cDNA from single cells that passed the initial quality check was diluted to $0.3 \mu \mathrm{g} / \mathrm{ml}$. 379 single-neuron cDNA extracts were library prepped using the Nextera DNA library prep protocol (Illumina \#FC-121-1012). The cDNA was then sequenced on a HiSeq 2500 in the Vincent J. Coates Genomics Sequencing Laboratory at UC Berkeley.

\section{Single-cell RNA-seq preprocessing}

Reads were aligned to the GRCm38.3 (mm10, patch release 3) mouse genome assembly with Tophat2 ( $\mathrm{v}$. 2.1.1; Kim et al., 2013), and low-quality reads were removed with Trimmomatic (v. 0.3.2; Bolger et al., 2014). Gene expression was quantified using featureCounts ( $v$. 1.5.0-p3; Liao et al., 2014) and RefSeq transcript annota- tion. Reads that aligned to more than one gene as well as chimeric fragments were excluded. We used a quality control (QC) pipeline that computes an extensive set of quality metrics, relying in part on FastQC (v. 0.3.2) and the Picard tools (v. 2.5.0 with samtools 1.3.1) as done previously (Fletcher et al., 2017). We used the Bioconductor package scone (https://bioconductor.org/packages/scone; v. 0.99.6) to perform data-adaptive cell and gene filtering. This yielded the following exclusion criteria: any cell with fewer than 500,000 aligned reads or a percentage of aligned reads below $85 \%$. In addition, we filtered out cells with large dropout rates, as defined by the "false-negative curves" of scone. This procedure resulted in a total of 232 retained cells (out of 379). Finally, we retained only those genes having at least 10 reads in at least 10 cells $(10,983$ genes).

\section{Single-cell RNA-seq statistical analysis}

We performed and assessed several normalization schemes using scone (Cole et al., 2017) and selected fullquantile normalization (Bolstad et al., 2003; Bullard et al., 2010). We then applied principal component analysis on the normalized data and retained the first 50 principal components, which explained $41 \%$ of the variance. Cluster analysis was performed on the first 50 principal components using the RSEC method (Risso et al., 2018b) implemented in the Bioconductor package clusterExperiment (https://bioconductor.org/packages/clusterExperiment; v. 1.0.0), as previously described (Fletcher et al., 2017). We used RSEC with the following specific parameters: alphas $=0.3$, minSizes $=5$, combineProportions $=$ 0.5 ; all other parameters were left at their default values. RSEC found 9 stable clusters. We used limma (v. 3.30.13) with voom correction weights (Law et al., 2014), as implemented in the clusterExperiment function getBestFeature, to find marker genes for each cluster. To visualize the clustering results, we applied ZINB-WaVE (Risso et al., 2018a; with $\mathrm{K}=10$ ) for dimensionality reduction, followed by $\mathrm{t}$-distributed stochastic neighbor embedding (t-SNE; perplexity parameter set to 20; van der Maaten and Hinton, 2008).

\section{Accession number and code accessibility}

The accession number for the RNA-seq data reported in this paper is GEO: GSE115070. The computer code for the single-cell RNA-seq analysis is available at https:// github.com/drisso/striatum. This code was run on an Apple Mac computer with macOS Sierra 10.12.4 operating system.

\section{Fluorescent in situ hybridization}

To visualize mRNA we used the RNAScope fluorescent in situ hybridization (FISH) method (ACDBio). Fresh-frozen tissue was processed as per RNAScope instructions. Briefly, mouse brain tissue from male and female mice aged P21-P120 was fresh-frozen in OCT on dry ice and stored at least overnight at $-80^{\circ} \mathrm{C}$. Tissue was then cut on a cryostat (Leica Microm HM550) into $12 \mu \mathrm{m}$ sections and mounted onto slides. Slides were fixed in 4\% PFA in 1X PBS for $15 \mathrm{~min}$. Slides were dehydrated using $5 \mathrm{~min}$ incubations in 50\%, 70\%, and twice with $100 \%$ ethanol. 
Slides were incubated with RNAScope Protease IV (ACDBio \#322340) at RT for 30 min and washed with $1 \times$ PBS. FISH was then performed using the RNAScope Multiplex Fluorescent assay (ACDBio \#320850) per the manufacturer's instructions and protocols. Following FISH, slides were coverslipped using ProLong Gold Antifade mounting media (Invitrogen \#P36934). RNAScope probes used: mM-Neurod6 (\#444851), mM-Grp (\#317861), mM-Th (\#317621), mM-Slc6a3 (\#315441), mM-Lypd1 (\#447081).

\section{Microscopy and image analysis}

Two confocal microscopes were used to take Z-stack images of FISH-labeled or immunostained sections: an Olympus FV1000 with a $20 \times$ Nikon objective and a Zeiss LSM 710 AxioObserver with Zeiss $10 \times, 20 \times$, and $63 \times$ objectives housed in the Molecular Imaging Center at UC Berkeley. Images were analyzed using the Fiji image analysis toolbox. Cells were considered positive for Neurod6, Grp, or Lypd1 if they contained three fluorescent puncta within the boundary created by a cell marker: S/c6a3 (DAT), Th, or DAPI.

\section{Retrobead and virus intracranial injections}

P14-P18 wild-type male and female mice were used for retrograde labeling experiments. Green Retrobeads IX (Lumaflour \#G180) were diluted 1:7 in sterile $1 \times$ PBS unless otherwise noted. Beads were bilaterally injected using a pulled glass pipette. The following coordinates from bregma and bead volumes were used to target each projection site: dorsomedial striatum (DMS; M/L \pm 1.35 $\mathrm{mm}, \mathrm{A} / \mathrm{P}+0.75 \mathrm{~mm}, \mathrm{D} / \mathrm{N}-2.60 \mathrm{~mm}, 400 \mathrm{nl}$ beads), dorsolateral striatum (DLS; M/L $\pm 2.15 \mathrm{~mm}, A / P+0.70 \mathrm{~mm}$, $\mathrm{D} / \mathrm{V}-2.50 \mathrm{~mm}, 400 \mathrm{nl}$ beads), nucleus accumbens (NAc) medial shell $(\mathrm{M} / \mathrm{L} \pm 0.75 \mathrm{~mm}, \mathrm{~A} / \mathrm{P}+1.20 \mathrm{~mm}, \mathrm{D} / \mathrm{V}-4.15$ $\mathrm{mm}, 300 \mathrm{nl}$ beads), NAc core (M/L +/1.2 mm, A/P +1.10 $\mathrm{mm}, \mathrm{D} / \mathrm{V}-4.05 \mathrm{~mm}, 300 \mathrm{nl}$ beads), NAc lateral shell (M/L $\pm 1.75 \mathrm{~mm}, \mathrm{~A} / \mathrm{P}+1.05 \mathrm{~mm}, \mathrm{D} / \mathrm{V}-3.95 \mathrm{~mm}, 300 \mathrm{nl}$ beads), basolateral amygdala (M/L $\pm 2.65 \mathrm{~mm}, \mathrm{~A} / \mathrm{P}-1.05 \mathrm{~mm}, \mathrm{D} / \mathrm{N}$ $-4.40 \mathrm{~mm}, 120 \mathrm{nl}$ beads at 1:3 dilution), medial prefrontal cortex (four injections per hemisphere at two different depths per injection: $M / L \pm 0.35 \mathrm{~mm}, A / P+1.50 \mathrm{~mm}$, $+1.65 \mathrm{~mm},+1.80 \mathrm{~mm}$, and $+1.95 \mathrm{~mm}, \mathrm{D} / \mathrm{N}-2.00 \mathrm{~mm}$ and $-1.40 \mathrm{~mm}, 400 \mathrm{nl}$ total per hemisphere), and lateral septum (M/L $\pm 0.45 \mathrm{~mm}, \mathrm{~A} / \mathrm{P}+0.40 \mathrm{~mm}, \mathrm{D} / \mathrm{V}-2.70 \mathrm{~mm}$, $300 \mathrm{nl}$ beads).

To allow for sufficient DA neuron labeling, mice were sacrificed at various time points following injection: $7 \mathrm{~d}$ for the DMS and DLS, $21 \mathrm{~d}$ for the prefrontal cortex, and 14 $d$ for the NAc (medial shell, core, and lateral shell), lateral septum and amygdala. Brains were harvested and cut to separate the injection site and midbrain. The midbrain was frozen for cryostat sectioning as described above for $\mathrm{FISH}$. The brain region containing the injection site was incubated in $4 \%$ PFA overnight at $4^{\circ} \mathrm{C}$, then cryoprotected in $30 \%$ sucrose in $1 \times$ PB until the tissue sank. Injection site tissue was sectioned on a freezing microtome, mounted with Vectashield hardset mounting media with DAPI (Vector laboratories \#H-1500), and analyzed for bead expression at the injection site. Brains with correctly targeted injection sites and minimal off-target bead expression were chosen for analysis.
To selectively label NEX-Cre-expressing neurons in the VTA, we unilaterally injected $800 \mathrm{nl}$ of a Cre-dependent tdTomato virus (AAV1.CAG.Flex.tdTomato.WPRE.bGH, Penn Vector Core \#AV-1-ALL864) into heterozygous NEXCre mice at P16. To target the VTA, we used the following coordinates from bregma: $\mathrm{M} / \mathrm{L} \pm 0.25 \mathrm{~mm}, \mathrm{~A} / \mathrm{P}-2.9 \mathrm{~mm}$, $\mathrm{D} / \mathrm{V}-4.45 \mathrm{~mm}$.

\section{Immunohistochemistry}

Immunohistochemistry was performed as described previously (Bateup et al., 2013). The following antibodies were used: tyrosine hydroxylase (TH, ImmunoStar \#22941, RRID:AB_572268), Alexa Fluor 488 goat anti-mouse secondary (Thermo Fisher Scientific \#A-11001, RRID: AB_2534069), Alexa Fluor 633 goat anti-mouse secondary (Thermo Fisher Scientific \#A-21050, RRID:AB_2535718), streptavidin Alexa Fluor 488 conjugate (Thermo Fisher Scientific \#S32354, RRID:AB_2315383), and streptavidin Alexa Fluor 633 conjugate (Thermo Fisher Scientific \#S21375, RRID:AB_2313500).

\section{Electrophysiology}

275- $\mu \mathrm{m}$-thick coronal midbrain slices were prepared from P56-P105 NEX-Cre;Ai9 or DAT $T^{\mathrm{IRES}}$ Cre;Ai9 mice of both sexes on a vibratome (Leica VT1000 S) in ice-cold high $\mathrm{Mg}^{2+}$ ACSF containing, in $\mathrm{mm}: 85 \mathrm{NaCl}, 25 \mathrm{NaHCO}_{3}$, $2.5 \mathrm{KCl}, 1.25 \mathrm{NaH}_{2} \mathrm{PO}_{4}, 0.5 \mathrm{CaCl}_{2}, 7 \mathrm{MgCl}_{2}, 10$ glucose, and 65 sucrose. Slices were recovered for $15 \mathrm{~min}$ at $34^{\circ} \mathrm{C}$ followed by 50 min at RT in ACSF containing, in mM: 130 $\mathrm{NaCl}, 25 \mathrm{NaHCO}_{3}, 2.5 \mathrm{KCl}, 1.25 \mathrm{NaH}_{2} \mathrm{PO}_{4}, 2 \mathrm{CaCl}_{2}, 2$ $\mathrm{MgCl}_{2}$, and 10 glucose. NEX-Cre ${ }^{+}$VTA neurons were identified by tdTomato fluorescence in NEX-Cre;Ai9 mice. SNc neurons were defined either by the presence of green retrobeads injected into the dorsolateral striatum in NEXCre;Ai9 mice or by tdTomato fluorescence and anatomic location in DAT ${ }^{\mathrm{IRES}}$ Cre;Ai9 mice. For whole-cell recordings, $2.5-6 \mathrm{~m} \Omega$ glass pipettes were filled with a potassium-based internal solution containing, in $\mathrm{mM}$ : 135 $\mathrm{KMeSO}_{3}, 5 \mathrm{KCl}, 5$ HEPES, 4 Mg-ATP, $0.3 \mathrm{Na}-\mathrm{GTP}, 10$ phospho-creatine, $1 \mathrm{EGTA}$, and $4 \mathrm{mg} / \mathrm{ml}$ neurobiotin (Vector laboratories \#SP-1120). Recordings were obtained using a MultiClamp 700B amplifier (Molecular Devices) and Scanlmage software. Passive membrane properties were recorded in voltage clamp with the membrane held at $-70 \mathrm{mV}$. Spontaneous action potentials were recorded in current clamp. In current clamp, $500 \mathrm{~ms}$ steps of negative current were delivered (-25 to $-150 \mathrm{pA})$ to hyperpolarize the membrane to approximately -100 $\mathrm{mV}$. During the steps, current was injected to maintain the baseline membrane potential at $-70 \mathrm{mV}$. All recordings were performed at RT in the presence of synaptic blockers (NBQX $10 \mu \mathrm{M}$, CPP $10 \mu \mathrm{M}$, picrotoxin $50 \mu \mathrm{M}$, final concentration). Data were analyzed in Igor (Wavemetrics) using custom scripts.

\section{6-OHDA injection}

6-hydroxydopamine (6-OHDA; 6-hydroxydopamine hydrobromide with ascorbic acid: Sigma-Aldrich \#H116$5 \mathrm{MG})$ injections were made into the medial forebrain bundle of P120 female mice as previously described (Thiele et al., 2012). 30 min before 6-OHDA injection, a 
solution containing $0.5 \mathrm{mg} / \mathrm{ml}$ pargyline (Sigma Aldrich \#P8013) and $2.5 \mathrm{mg} / \mathrm{ml}$ desipramine hydrochloride (Tocris \#3067) was injected i.p. at a dose of $5 \mathrm{mg} / \mathrm{kg}$ pargyline and $25 \mathrm{mg} / \mathrm{kg}$ desipramine. $200 \mathrm{nl}$ of freshly prepared 15 $\mathrm{mg} / \mathrm{ml} 6-\mathrm{OHDA}$ in sterile saline $+0.02 \%$ ascorbic acid were injected into the medial forebrain bundle (MFB, coordinates from bregma: $M / L \pm 1.2 \mathrm{~mm}, A / P 1.2 \mathrm{~mm}, \mathrm{D} / \mathrm{V}$ $-4.90 \mathrm{~mm}$ ). Adult female wild-type mice were used as younger mice and male mice showed poor recovery following injection. 250-350 $\mu$ l of meloxicam $(5-10 \mathrm{mg} / \mathrm{kg}$ dose) was injected subcutaneously as an analgesic.

Mice were monitored daily following the injection to ensure recovery. Kitten Milk Replacement (Santa Cruz \#sc-362120) was fed to mice daily for up to 2 wk following the injection to aid recovery and meloxicam was injected subcutaneously to alleviate pain if necessary. Motor function was assessed using the cylinder test each week following the injection (see below). 4 wk following 6-OHDA injection, mice were quickly anesthetized using isoflurane and decapitated, and their brains were fresh-frozen as described above for FISH.

\section{Cylinder test}

To test the severity of Parkinsonian-like symptoms following unilateral 6-OHDA injection, we used the cylinder test to score limb use asymmetry. Mice were habituated to the behavior room for a minimum of 30 min during their dark cycle under red light illumination. Mice were placed into a clear plastic cylinder $12 \mathrm{~cm}$ in diameter and $20 \mathrm{~cm}$ in height. The cylinder was placed next to two mirrors to visualize paw use. The mouse was both video recorded and observed by the experimenter while it was allowed to move around freely in the cylinder for $10 \mathrm{~min}$. Full $360^{\circ}$ ipsiversive and contraversive rotations (relative to the 6 -OHDA injection side) were counted. Forelimb asymmetry was measured by counting the number of times the ipsilateral paw, contralateral paw, or both paws were used for support when the mouse reared against the wall of the cylinder. The percentage of ipsilateral or contralateral paw use was calculated based on total rears (e.g., ipsilateral paw touches/ipsilateral + contralateral + both paw touches). A greater number of ipsiversive turns and ipsilateral paw use indicates a successful 6-OHDA injection and unilateral Parkinsonian-like symptoms.

\section{Experimental design and statistical analysis}

A one-way ANOVA was used to compare the means of three or more groups. Post hoc pairwise comparisons were made using either Bonferroni's or Tukey's multiple comparisons tests. Unpaired or paired two-tailed $t$ tests were used to compare the means of two groups. A paired, one-way ANOVA with Dunnett's multiple comparisons post hoc test was used to compare DA neuron subpopulations to the entire VTA DA population for the 6-OHDA experiments. Data are reported as the mean \pm SEM. Superscript letters listed with $p$-values correspond to the statistical tests shown in Table 1. $p$-values were corrected for multiple comparisons.

\section{Results}

\section{Single-cell RNA-seq of midbrain dopamine neurons}

To define subclasses of DA neurons in an unbiased way, we performed single-cell RNA sequencing of DA neurons from P26-P34 male and female mice in which dopamine transporter (DAT)-expressing neurons were labeled with a tdTomato reporter (DAT ${ }^{\mathrm{IRES}} \mathrm{Cre}$;Ai9, Fig. 1-1A). A bioinformatic and statistical workflow revealed nine clusters of DA neurons based on differential gene expression (Fig. 1-1B-E and Table 1-1). We identified markers for each cluster and validated eight of the nine clusters. Two of the clusters corresponded to DA subpopulations in the hypothalamus, four defined subclasses of VTA neurons, and two corresponded to the SNc (Fig. 1-1F). These populations are consistent with recent single-cell DA neuron profiling studies (Poulin et al., 2014; La Manno et al., 2016; Romanov et al., 2017).

\section{Grp and Neurod6 define anatomically overlapping but distinct midbrain subpopulations}

Consistent with prior studies (Poulin et al., 2014; La Manno et al., 2016), we identified a cell cluster that showed relatively high and selective expression of Grp, Neurod6, and Gpr83 (cluster \#8, Fig. 1-1C). Given recent interest in Neurod6 and Grp as markers that label ventromedial VTA DA neurons (La Manno et al., 2016; Viereckel et al., 2016; Khan et al., 2017), we chose to quantitatively analyze their expression patterns in the midbrain and examine the extent of their overlap. Using multiplex FISH, we found that in adult mice, Grp-expressing neurons represented $29.9 \% \pm 0.5 \%$ of the total midbrain DA neuron population (1804/6407 neurons from 8 mice) and $35.9 \% \pm 0.4 \%$ of DA neurons in the VTA $(1570 / 4377$ neurons from 8 mice; Fig. $1 A-D) .97 .4 \% \pm 0.7 \%$ of Grp $^{+}$ cells in the midbrain were dopaminergic, defined by coexpression of tyrosine hydroxylase (Th) mRNA (1780/1822 cells from 4 mice). Grp ${ }^{+}$DA neurons were found in all subregions of the VTA but were enriched in the ventromedial portions of the VTA, the interfascicular nucleus (IF), and paranigral/parainterfascicular nuclei (PN/PIF; $p<$ $0.0001,{ }^{\text {a }}$ one-way ANOVA with Tukey's post hoc test, Fig. $1 E$ ). Notably, while Grp was previously identified as a VTA marker (Chung et al., 2005; Greene et al., 2005; Viereckel et al., 2016), we also found Grp-expressing DA neurons in the ventromedial portion of the SNc $(22.7 \% \pm 1.8 \%$ of DA neurons in this region, Fig. $1 A-F$ ).

Neurod6 expression defined a more restricted DA population, accounting for $26.8 \% \pm 0.5 \%$ of VTA DA neurons (1172/4377 neurons from 8 mice), with the highest density of Neurod6 $6^{+}$DA neurons in the ventromedial IF and PN/ PIF regions $\left(p<0.0001,{ }^{\text {b }}\right.$ one-way ANOVA with Tukey's post hoc test, Fig. 1E). In contrast to Grp, Neurod6 mRNA was not expressed in the SNc (Fig. 1A-F). 93.1\% $\pm 0.6 \%$ of Neurod $66^{+}$VTA neurons were dopaminergic (948/1016 cells from 4 mice). Consistent with our RNA-seq data, we found that most, but not all, Neurod6 ${ }^{+}$DA neurons coexpressed $\operatorname{Grp}(77.5 \% \pm 0.8 \%, 909 / 1172$ cells from 8 mice). Broken down by subregion, the majority of Neurod $6^{+}$DA neurons in the IF and PN/PIF coexpressed Grp; however, a third of Neurod $6{ }^{+}$DA neurons in the PBP did not have 
Table 1. Statistical analysis

\begin{tabular}{|c|c|c|c|c|c|}
\hline Location & Data structure & Type of test & $\mathrm{Cl} /$ power & $P$ value & Comparison \\
\hline \multirow[t]{11}{*}{ a } & Normally distributed & One-way ANOVA & 0.97 & $<0.0001$ & Grp expression in midbrain subregions \\
\hline & Normally distributed & Tukey's post hoc & 6.508 to 17.74 & $<0.0001$ & Grp IF vs. PN/PIF \\
\hline & Normally distributed & Tukey's post hoc & 34.77 to 46 & $<0.0001$ & Grp IF vs. PBP \\
\hline & Normally distributed & Tukey's post hoc & 35.1 to 46.33 & $<0.0001$ & Grp IF vs. SNc-V \\
\hline & Normally distributed & Tukey's post hoc & 57.26 to 68.49 & $<0.0001$ & Grp IF vs. SNc-D \\
\hline & Normally distributed & Tukey's post hoc & 22.65 to 33.88 & $<0.0001$ & Grp PN/PIF vs. PBP \\
\hline & Normally distributed & Tukey's post hoc & 22.97 to 34.2 & $<0.0001$ & Grp PN/PIF vs. SNc-V \\
\hline & Normally distributed & Tukey's post hoc & 45.13 to 56.37 & $<0.0001$ & Grp PN/PIF vs. SNc-D \\
\hline & Normally distributed & Tukey's post hoc & -5.292 to 5.942 & 0.9998 & Grp PBP vs. SNc-V \\
\hline & Normally distributed & Tukey's post hoc & 16.87 to 28.1 & $<0.0001$ & Grp PBP vs. SNc-D \\
\hline & Normally distributed & Tukey's post hoc & 16.55 to 27.78 & $<0.0001$ & Grp SNc-V vs. SNcD \\
\hline \multirow[t]{12}{*}{ b } & Normally distributed & One-way ANOVA & 0.96 & $<0.0001$ & $\begin{array}{l}\text { Neurod } 6 \text { expression in midbrain } \\
\text { subregions }\end{array}$ \\
\hline & Normally distributed & Tukey's post hoc & -0.4177 to 9.918 & 0.0842 & Neurod6 IF vs. PN/PIF \\
\hline & Normally distributed & Tukey's post hoc & 16.28 to 26.62 & $<0.0001$ & Neurod6 IF vs. PBP \\
\hline & Normally distributed & Tukey's post hoc & 34.69 to 45.03 & $<0.0001$ & Neurod6 IF vs. SNc-V \\
\hline & Normally distributed & Tukey's post hoc & 35.82 to 46.16 & $<0.0001$ & Neurod6 IF vs. SNc-D \\
\hline & Normally distributed & Tukey's post hoc & 11.53 to 21.87 & $<0.0001$ & Neurod6 PN/PIF vs. \\
\hline & Normally distributed & Tukey's post hoc & & & PBP \\
\hline & Normally distributed & Tukey's post hoc & 29.94 to 40.28 & $<0.0001$ & Neurod6 PN/PIF vs. SNc-V \\
\hline & Normally distributed & Tukey's post hoc & 31.07 to 41.41 & $<0.0001$ & Neurod6 PN/PIF vs. SNc-D \\
\hline & Normally distributed & Tukey's post hoc & 13.24 to 23.58 & $<0.0001$ & Neurod6 PBP vs. SNc-V \\
\hline & Normally distributed & Tukey's post hoc & 14.37 to 24.71 & $<0.0001$ & Neurod6 PBP vs. SNc-D \\
\hline & Normally distributed & Tukey's post hoc & -4.043 to 6.293 & 0.9699 & Neurod6 SNc-V vs. SNc-D \\
\hline \multirow[t]{4}{*}{ c } & Normally distributed & One-way ANOVA & 0.522 & 0.036 & Grp expression by age \\
\hline & Normally distributed & Tukey's post hoc & -1.112 to 2.462 & 0.5636 & Grp 2 wk vs. 8 wk \\
\hline & Normally distributed & Tukey's post hoc & -3.087 to 0.4872 & 0.1603 & Grp 2 wk vs. 16 wk \\
\hline & Normally distributed & Tukey's post hoc & $\begin{array}{l}-3.762 \text { to }- \\
0.1878\end{array}$ & 0.0316 & Grp 8 wk vs. 16 wk \\
\hline \multirow[t]{4}{*}{$d$} & Normally distributed & One-way ANOVA & 0.56 & 0.0236 & Neurod6 expression by age \\
\hline & Normally distributed & Tukey's post hoc & -2.859 to 1.109 & 0.4655 & Neurod6 2 wk vs. 8 wk \\
\hline & Normally distributed & Tukey's post hoc & $\begin{array}{l}-4.384 \text { to }- \\
0.4162\end{array}$ & 0.0201 & Neurod6 2 wk vs. 16 wk \\
\hline & Normally distributed & Tukey's post hoc & -3.509 to 0.4588 & 0.1351 & Neurod6 8 wk vs. 16 wk \\
\hline e & Normally distributed & Unpaired $t$ test & -7.68 to 3.147 & 0.3728 & Grp IF M vs. F \\
\hline$f$ & Normally distributed & Unpaired $t$ test & -12.78 to 0.4155 & 0.0634 & Grp PN/PIF M vs. F \\
\hline g & Normally distributed & Unpaired $t$ test & -1.924 to 4.89 & 0.3549 & Grp PBP M vs. F \\
\hline $\mathrm{h}$ & Normally distributed & Unpaired $t$ test & -7.321 to 5.188 & 0.7119 & Grp SNCv M vs. F \\
\hline i & Normally distributed & Unpaired $t$ test & -0.6657 to 1.199 & 0.5383 & Grp SNCd M vs. F \\
\hline j & Normally distributed & Unpaired $t$ test & -13.48 to 4.412 & 0.2852 & Neurod6 IF M vs. F \\
\hline $\mathrm{k}$ & Normally distributed & Unpaired $t$ test & -8.615 to 3.682 & 0.3924 & Neurod6 PN/PIF M vs. F \\
\hline 1 & Normally distributed & Unpaired $t$ test & -1.028 to 2.095 & 0.4642 & Neurod6 PBP M vs. F \\
\hline $\mathrm{m}$ & Normally distributed & Unpaired $t$ test & -2.251 to 0.1514 & 0.0801 & Neurod6 SNCv M vs. F \\
\hline $\mathrm{n}$ & Negative binomial & Likelihood ratio test & $\mathrm{n} / \mathrm{a}$ & 0.5113 & Neurod6 M vs. F RNASeq data \\
\hline o & Negative binomial & Likelihood ratio test & $\mathrm{n} / \mathrm{a}$ & 0.6835 & Grp M vs. F RNASeq data \\
\hline$p$ & Normally distributed & Unpaired $t$ test & -9.156 to -1.532 & 0.0075 & Vm - SNc vs. NEXCre \\
\hline q & Normally distributed & Unpaired $t$ test & -1222 to -729.4 & $<0.0001$ & Rm - SNc vs. NEXCre \\
\hline r & Normally distributed & Unpaired $t$ test & 23.67 to 43.99 & $<0.0001$ & Cm - SNc vs. NEXCre \\
\hline s & Normally distributed & Unpaired $t$ test & 11.3 to 21.88 & $<0.0001$ & AP height - SNc vs. NEX-Cre \\
\hline $\mathrm{t}$ & Normally distributed & Unpaired $t$ test & 3.372 to 9.524 & 0.0002 & AHP - SNc vs. NEXCre \\
\hline u & Normally distributed & Unpaired $t$ test & 6.564 to 10.49 & $<0.0001$ & Sag - SNc vs. NEXCre \\
\hline $\mathrm{v}$ & Normally distributed & Unpaired $t$ test & 4.295 to 7.773 & $<0.0001$ & Rebound - SNc vs. NEX-Cre \\
\hline \multirow[t]{4}{*}{ w } & Normally distributed & One-way ANOVA & 0.85 & 0.0002 & Cylinder test \\
\hline & Normally distributed & Tukey's post hoc & 6.33 to 55.07 & 0.0163 & Saline vs. 6-OHDA paw \\
\hline & Normally distributed & Tukey's post hoc & -55.27 to -6.53 & 0.0157 & Saline vs. both paws \\
\hline & Normally distributed & Tukey's post hoc & -85.97 to -37.23 & 0.0002 & 6-OHDA vs. both paws \\
\hline \multirow[t]{5}{*}{$\mathrm{x}$} & Normally distributed & Paired one-way ANOVA & 0.96 & $<0.0001$ & Cell population survival \\
\hline & Normally distributed & Dunnett's post hoc & -69.31 to -34.69 & 0.0022 & All $\mathrm{TH}^{+}$vs. Grp-/ Neurod6 ${ }^{+}$ \\
\hline & Normally distributed & Dunnett's post hoc & -6.01 to 15.16 & 0.3169 & All $\mathrm{TH}^{+}$vs. Grp ${ }^{+} / \mathrm{Neurod}^{+}$ \\
\hline & Normally distributed & Dunnett's post hoc & 2.07 to 15.78 & 0.0246 & All $\mathrm{TH}^{+}$vs. Grp ${ }^{+} /$Neurod6- \\
\hline & Normally distributed & Dunnett's post hoc & 0.6149 to 15.14 & 0.0403 & All $\mathrm{TH}^{+}$vs. Lypd1+/Neurod6- \\
\hline $\mathrm{y}$ & Normally distributed & Paired $t$ test & -3.593 to 3.043 & 0.8091 & Lypd $1^{+} /$Neurod $^{+}$saline vs. $6-\mathrm{OHDA}$ \\
\hline
\end{tabular}



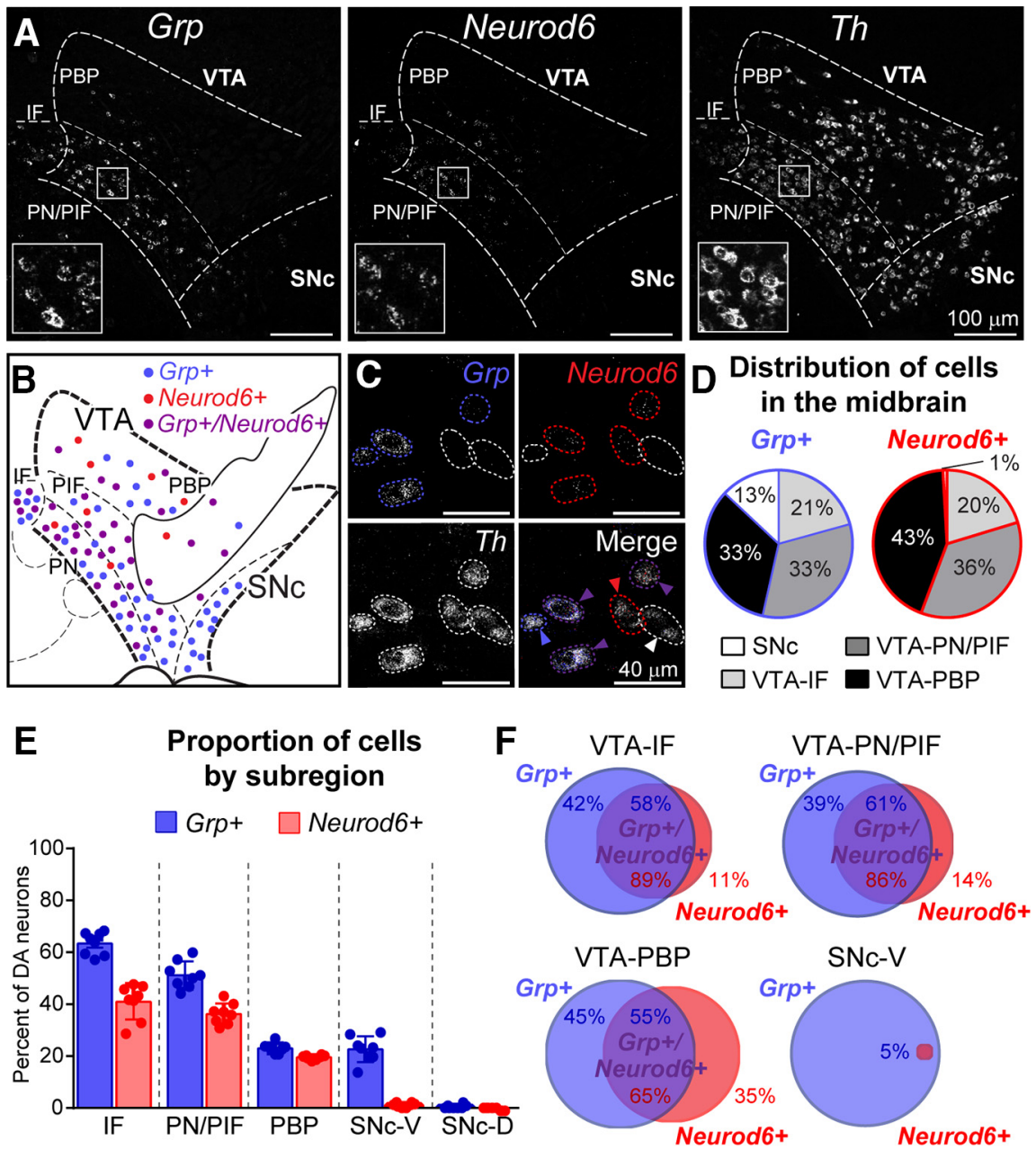

SNc-V

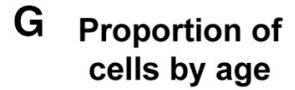

Proportion of cells by subregion and sex

Grp

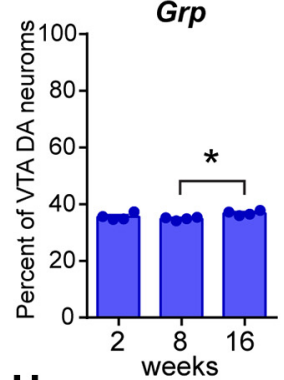

Grp
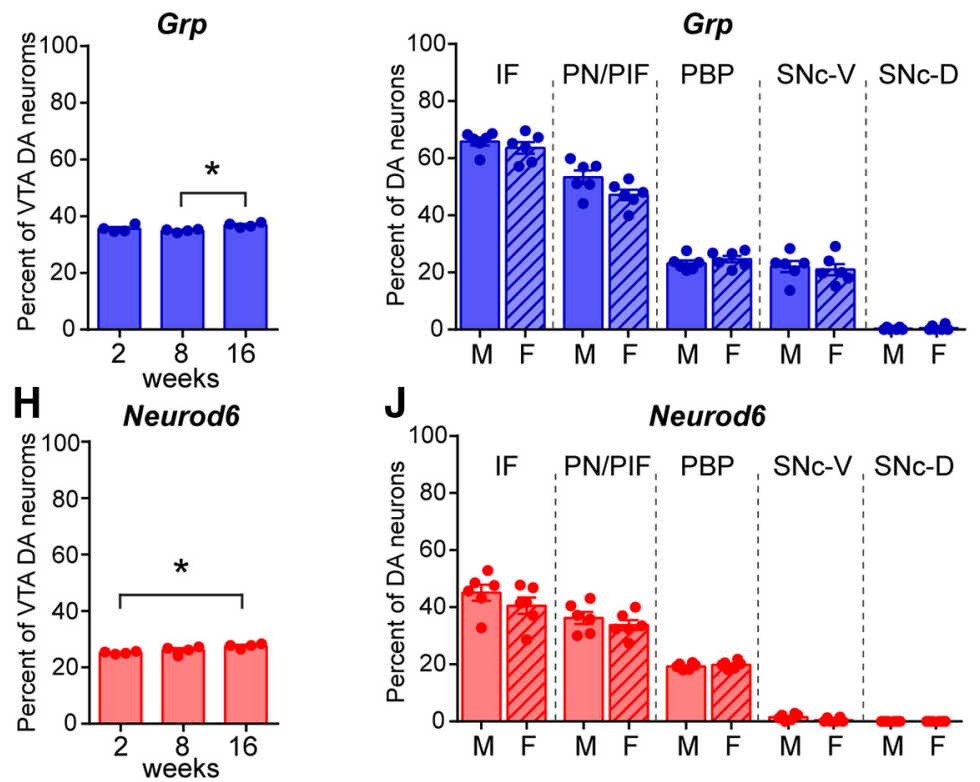

Figure 1. Anatomic analysis of Grp and Neurod6-expressing DA neurons in the midbrain. A, Confocal images of multiplex fluorescent in situ hybridization using probes against Grp (left), Neurod6 (middle), and tyrosine hydroxylase (Th, right) mRNA. Inset boxes show higher-magnification images of the boxed regions. B, Schematic showing the location of Grp ${ }^{+}$(blue), Neurod6 ${ }^{+}$(red), and 


\section{continued}

$\mathrm{Grp}^{+} /$Neurod6 $^{+}$(purple) DA neurons in the midbrain. C, High-magnification confocal images showing Th-positive VTA neurons expressing Grp (blue circles), Neurod6 (red circles), Grp and Neurod6 (purple circles), or neither marker (white circles). D, Charts show the distribution of $\mathrm{Grp}^{+}$or Neurod6 ${ }^{+}$neurons across different midbrain regions, expressed as a percentage of the total Grp ${ }^{+}$or Neurod $6^{+}$population. Only DA neurons, defined by expression of Th mRNA, were included in the analysis, $n=4377$ cells quantified from 8 mice (4 male and 4 female). E, Quantification of the number of $T^{+}$DA neurons that coexpress Grp or Neurod6 in subregions of the VTA and SNc. Bars represent mean \pm SEM, dots represent the values from individual mice, $n=4377 \mathrm{Th}^{+}$cells quantified from 4 male and 4 female mice. Grp one-way ANOVA, $p<0.0001$; Tukey's post hoc tests revealed significant $(p<0.0001)$ differences for each subpopulation compared to all others except the PBP versus SNc-V ( $p=0.9998)$. Neurod6 one-way ANOVA, $p<0.0001$; Tukey's post hoc tests revealed significant $(p<0.0001)$ differences for each subpopulation compared to all others except the IF versus PN/PIF ( $p=0.0842)$ and SNc-V versus SNc-D $(p=0.9699)$. $\boldsymbol{F}$, Venn diagrams display the extent of overlap between the Grp and Neurod6-expressing DA neuron populations across four midbrain subregions. 1833 cells were quantified from 8 mice $(4$ male and 4 female). $\mathbf{G}, \boldsymbol{H}$, Graphs display the mean \pm SEM percentage of $\operatorname{Grp}^{+}(\boldsymbol{G})$ or Neurod6 $6^{+}(\boldsymbol{H})$ DA neurons in the VTA at 2, 8, and 16 wk. Statistical comparisons were made with a one-way ANOVA with Tukey's post hoc test; Grp 8 wk (34.9\%) vs. 16 wk (36.9\%), *, $p=$ 0.0316, Neurod6 2 wk (25.2\%) vs. 16 wk (27.6\%), *, $p=0.0201$. Dots represent values from individual mice, $n=2053-2324$ cells from 2 male and 2 female mice per time point. I, J, Graphs display the mean \pm SEM percentage of $\operatorname{Grp}^{+}(\boldsymbol{I})$ or Neurod6 $6^{+}(\boldsymbol{J})$ DA neurons across subregions of the VTA and SNc in male (M) and female (F) mice. Unpaired $t$ tests between males and females for each region revealed no significant sex differences. Dots represents values from individual mice, $n=3586$ cells from 6 male mice and 3424 cells from 6 female mice. IF, interfascicular nucleus; PN/PIF, paranigral/parainterfascicular nuclei; PBP, parabrachial pigmented nucleus; SNc-V, substantia nigra pars compacta-ventral portion; SNc-D, substantia nigra pars compacta-dorsal portion. See also Fig. $1-1$

detectable expression of Grp (Fig. 1F). Grp-expressing but Neurod6-lacking DA neurons were found throughout the VTA, and nearly all of the Grp ${ }^{+}$DA neurons in the SNc were lacking Neurod6 (Fig. 1F).

Together, these data show that Grp is expressed in a subpopulation of midbrain DA neurons spanning the VTA and ventromedial portion of the SNc. Neurod6 is expressed in a more restricted midbrain population, defining a subgroup of the Grp ${ }^{+}$DA population, which is located exclusively in the VTA. In addition, there is a small subset of VTA DA neurons that express Neurod6 but not Grp.

To determine if these cell populations were present throughout development, we assessed Grp and Neurod6 expression at multiple ages. We found that while there were subtle increases in the percentages of $\mathrm{Grp}^{+}$VTA DA neurons from 8 to 16 wk $\left(p=0.036,{ }^{\circ}\right.$ one-way ANOVA with Tukey's post hoc test, Fig. 1G) and Neurod6 ${ }^{+}$VTA DA neurons from 2 to 16 wk $\left(p=0.024,{ }^{d}\right.$ one-way ANOVA with Tukey's post hoc test, Fig. $1 H$ ), the proportions of DA neurons expressing these markers were largely stable from 2 wk postnatal through adulthood (P14-P112). We also investigated whether these cell populations were similar between sexes. We found that the Grp- and Neurod6-expressing DA subpopulations were present in male and female mice in similar proportions throughout VTA and SNc subregions (see statistics worksheet for unpaired $t$ test $p$ values, ${ }^{\mathrm{e}-\mathrm{m}}$ Fig. $1 /, \mathcal{l}$ ). Furthermore, in the RNA-seq data, we found no significant differences in expression levels of Grp or Neurod6 between males and females (log2-fold-change of 1.70 for Neurod6, $p=0.51^{\text {n }}$ and 0.94 for Grp, $p=0.68^{\circ}$ in males versus females, likelihood ratio test). These data demonstrate that the Grp $^{+}$and Neurod $6^{+}$DA neuron populations are present in both sexes and stable over time.

\section{Grp and Neurod6-expressing neurons project to the nucleus accumbens medial shell}

VTA DA neurons comprise multiple subcircuits, which send projections to different brain regions with distinct functional consequences (Roeper, 2013). To determine if the Grp and Neurod6 DA populations have specific projection targets, we combined retrograde labeling from eight primary DA neuron projection sites with Grp and Neurod6 FISH (Fig. 2A and Fig. 2-1A). We found that of the DA neurons projecting to the medial shell of the nucleus accumbens (NAc), $75.0 \% \pm 1.1 \%$ were Grppositive and $70.4 \% \pm 2.5 \%$ were Neurod6-positive, indicating that these markers were expressed in the majority of medial shell-projecting DA neurons (Fig. 2B,C,F,H). Grp $^{+}$and Neurod6 ${ }^{+}$DA neurons also projected to the NAc core and lateral shell but represented a smaller fraction of the neurons projecting to these regions compared to the medial shell (Fig. 2F,H). When quantified as a percentage of the total marker-positive bead-labeled DA neurons across all injection sites, the NAc medial shell was the primary target region for both $\mathrm{Grp}^{+}$and Neurod6 ${ }^{+} \mathrm{DA}$ neurons (Fig. 2G,I). Together, these findings indicate a strong mesoaccumbens projection from Neurod $6^{+}$and $\mathrm{Grp}^{+}$VTA DA neurons.

We found that Neurod6 mRNA was largely absent from DA neurons projecting to regions outside of the NAc, indicating a selective output of the Neurod $66^{+}$DA neuron population (Fig. $2 \mathrm{H}, \mathrm{I}$ ). By contrast, Grp ${ }^{+}$DA neurons represented a substantial percentage $(47.3 \% \pm 2.4 \%)$ of DA neurons projecting to the dorsomedial striatum (DMS; Fig. $2 \mathrm{D}-\mathrm{G}) .87 .7 \% \pm 2.5 \%$ of the DMS-projecting Grppositive neurons were located in the ventromedial portion of the SNc (Fig. 2-1B), consistent with prior reports mapping dopaminergic projections to the DMS (Lerner et al., 2015). These neurons lacked expression of Neurod6, as essentially no DMS-projecting neurons were Neurod6positive (Fig. $2 H, I)$. Taken together, these results indicate that there are at least two populations of DA neurons that express Grp: those located in the VTA that project primarily to the medial NAc and those in the ventromedial SNc, which project selectively to the DMS (Fig. 2-1B,C).

A recent study showed that Neurod6-expressing DA neurons, labeled by a Cre reporter in NEX-Cre mice [Neu- 


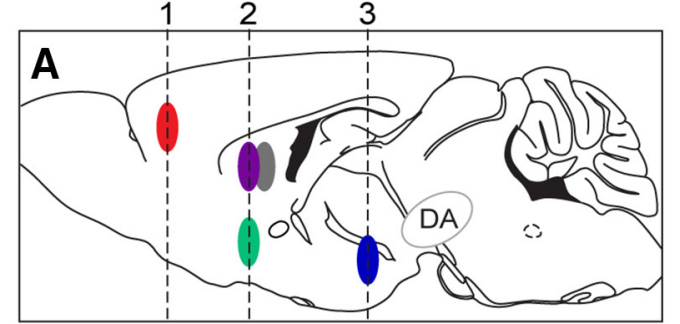

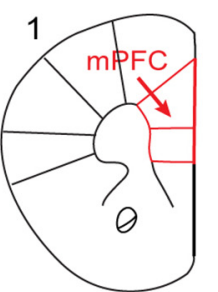

Prefrontal

Cortex

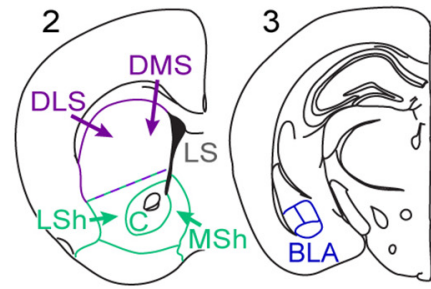

Striatum and

Basolateral

F

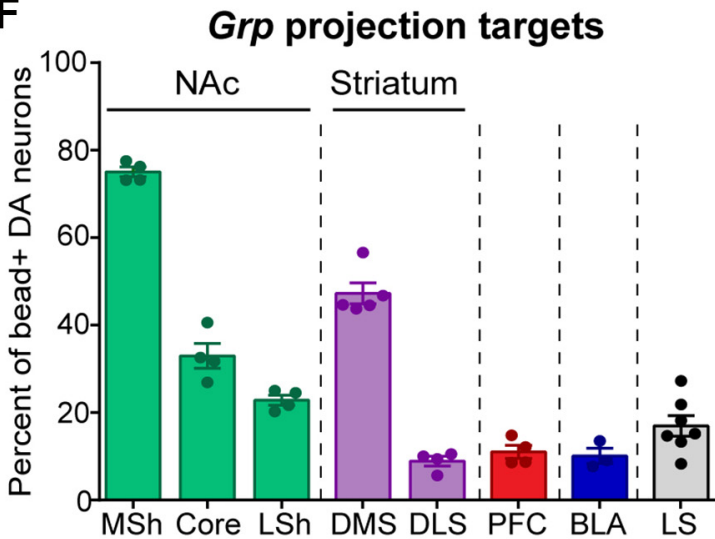

H

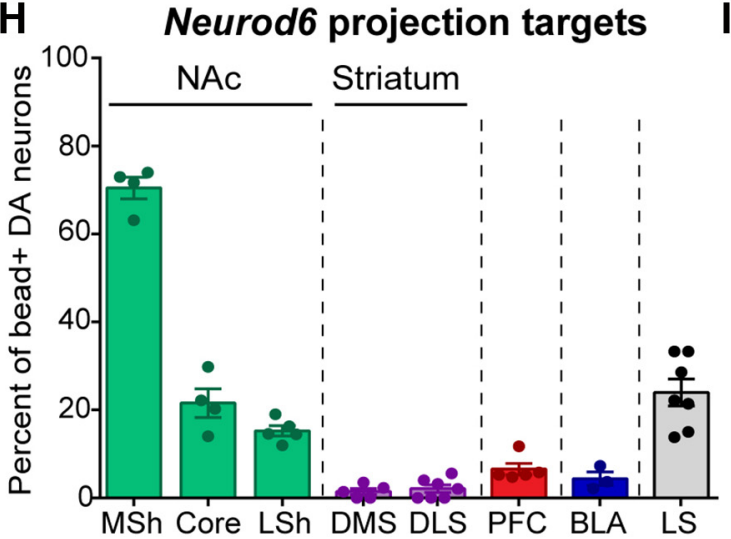

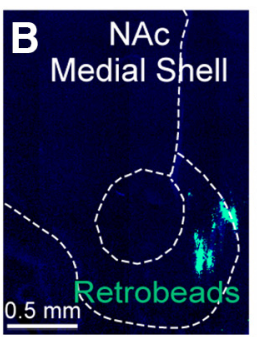
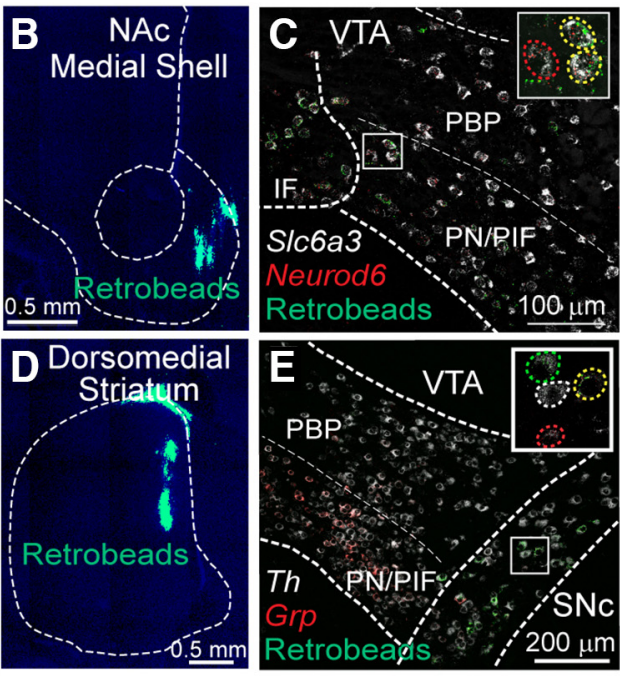

G Percent of Grp+/bead+ cells projecting to each region

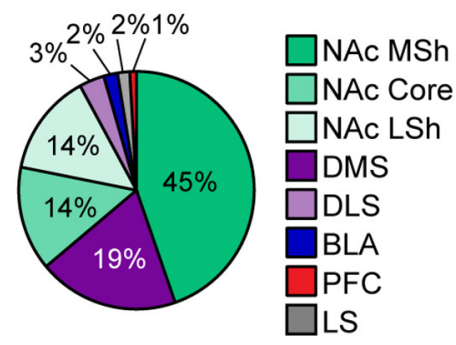

Percent of Neurod6+/bead+ cells projecting to each region

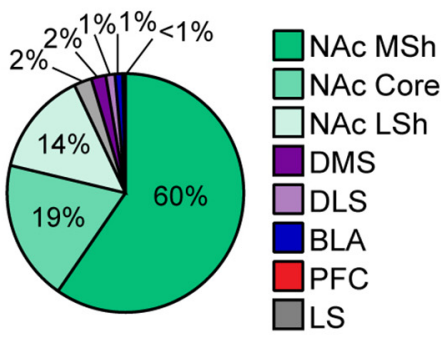

Figure 2. Projection targets of $\mathrm{Grp}^{+}$or Neurod6 ${ }^{+}$DA neurons. A, Schematic of retrobead injection sites in sagittal view. Numbers correspond to the coronal section schematics below showing the eight projection target sites. mPFC, medial prefrontal cortex; DLS, dorsolateral striatum; DMS, dorsomedial striatum; LSh, lateral shell; C, core; MSh, medial shell; LS, lateral septum; BLA, basolateral amygdala. $\boldsymbol{B}$, Image showing a green fluorescent retrobead injection into the nucleus accumbens (NAc) medial shell with DAPI staining in blue. C, Image of the VTA showing fluorescent in situ hybridization (FISH) for S/c6a3 (DAT) mRNA (white), Neurod6 mRNA (red), and green retrobeads from a NAc medial shell injection. $\boldsymbol{D}$, Image showing a green retrobead injection into the dorsomedial striatum (DMS) with DAPI staining in blue. $\boldsymbol{E}$, FISH image of the midbrain showing Th mRNA (white), Grp mRNA (red), and green retrobeads from a DMS injection. Insets boxes in $\boldsymbol{C}$ and $\boldsymbol{E}$ show higher-magnification images of the boxed regions. Red circles identify Neurod6 $^{+}(\boldsymbol{C})$ or $\mathrm{Grp}^{+}(\boldsymbol{E})$ neurons, green circles define bead-positive neurons, and yellow circles show bead-positive neurons expressing Neurod6 $(\boldsymbol{C})$ or Grp $(\boldsymbol{E})$. White circles identify neurons expressing Th only. $\boldsymbol{F}$, Quantification of the percentage of $T^{+}{ }^{+} / \mathrm{bead}^{+}$ midbrain neurons that coexpressed Grp mRNA for each of the projection sites. Bars represent mean \pm SEM, each dot represents one mouse. G, Summary of the projection targets of $\mathrm{Grp}^{+}$DA neurons expressed as a percentage of total bead ${ }^{+} / \mathrm{Grp}^{+} / \mathrm{Th}^{+}$neurons. $\boldsymbol{H}$, Quantification of the percentage of $\mathrm{DAT}^{+} / \mathrm{bead}^{+}$midbrain neurons that coexpressed Neurod 6 mRNA for each of the projection sites. 
continued

Bars represent mean \pm SEM, each dot represents one mouse. I, Summary of the projection targets of Neurod $6^{+}$DA neurons expressed as a percentage of total bead ${ }^{+} /$Neurod $^{+} / \mathrm{DAT}^{+}$neurons. For panels $\boldsymbol{F}$-I: NAc MSh $n=850$ cells from 2 male and 2 female mice, NAc Core $n=858$ cells from 2 males and 2 females, NAc LSh $n=1215$ cells from 3 males and 1-2 females, DMS $n=637$ cells from 3 males and 2 females, DLS $n=1038$ cells from 2-4 males and 2-3 females, mPFC $n=211$ cells from 3-4 males and 1 female, BLA $n=297$ cells from 3 males, and LS $n=345$ cells from 2 males and 4 females. See also Fig. 2-1.

rod6 was previously referred to as NEX (Goebbels et al., 2006)], project to the lateral septum (Khan et al., 2017). We found relatively few lateral septum-projecting neurons in the midbrain, of which $37.4 \% \pm 3.1 \%$ were nondopaminergic (92/252 cells from 4 mice). Of the DA neurons projecting to the lateral septum, $17.0 \% \pm 2.3 \%$ were $\mathrm{Grp}^{+}$and $24.0 \% \pm 3.0 \%$ were Neurod6 ${ }^{+}$(Fig. 2F,H). Quantified as a percentage of total bead-labeled neurons, $<2 \%$ of $\mathrm{Grp}^{+}$or Neurod6 ${ }^{+}$DA neurons projected to the lateral septum (Fig. 2G,l). These results indicate that compared to other brain regions, the lateral septum is not a major target for Grp- or Neurod6-expressing DA neurons.

\section{Neurod $6^{+}$DA neurons have unique physiological properties}

DA neurons projecting to different target areas possess distinct electrophysiological profiles (Lammel et al., 2008; Margolis et al., 2008; Lerner et al., 2015). To investigate whether Neurod6 expression defines a physiologically distinct subclass of DA neurons, we used NEX-Cre knock-in mice (Goebbels et al., 2006). We injected virus expressing a Cre-dependent tdTomato reporter (AAVFlex-tdTomato) into the midbrain and found NEX-Cre ${ }^{+}$DA neurons along the ventromedial portion of the VTA (Fig. $3 A$ ), consistent with the expression pattern of Neurod6 mRNA. In agreement with our tracing data, we found that tdTomato-labeled NEX-Cre ${ }^{+}$neurons projected to the NAc medial shell and core (Fig. $3 B$ ). To visualize NEX$\mathrm{Cre}^{+}$neurons for physiology, we crossed NEX-Cre mice to the Ai9 tdTomato Cre-reporter mouse line (Madisen et al., 2010). We performed FISH for Neurod6 mRNA in NEX-Cre;Ai9 mice (Fig. $3 C$ ) and found that $93.6 \% \pm 1.2 \%$ of tdTomato-positive DA neurons in the VTA coexpressed Neurod6 (331/353 cells from 4 mice), making this a suitable model to use for targeted electrophysiology recordings. Consistent with the $77.5 \%$ of Neurod $^{+}$neurons that coexpressed Grp, $73.7 \% \pm 2.9 \%$ of the NEX-Cre; tdTomato-positive VTA DA neurons expressed Grp (175/ 232 cells from 4 mice). We did observe that not all $\mathrm{Neu}$ rod $6^{+}$VTA DA neurons expressed tdTomato in the NEXCre;Ai9 mice $\left(30.4 \% \pm 1.7 \%\right.$ of Neurod $^{+}$DA neurons were tdTomato-positive, 361/1092 cells from 4 mice). In addition, a third of the tdTomato-positive midbrain neurons were non-dopaminergic $(36.9 \% \pm 3.4 \%$ Th negative, $193 / 546$ cells from 4 mice). This discrepancy may be due to transient Cre expression in non-DA neurons during development. These data suggest that NEX-Cre mice may not be appropriate for studies requiring selective access to the entire Neurod $66^{+}$VTA DA subpopulation, but can be used to target Neurod $6^{+}$cells for whole-cell recordings in which dopaminergic identity can be confirmed post hoc.

To determine if Neurod6-expressing neurons represent a functionally distinct cell class, we recorded from
tdTomato-labeled NEX-Cre ${ }^{+}$neurons in the VTA and analyzed their intrinsic membrane properties, action potential waveform, and response to hyperpolarizing current injection (see Fig. 3-1 for a summary of the physiology data including sample sizes). We confirmed that the NEX$\mathrm{Cre}^{+}$neurons analyzed were dopaminergic by filling patched neurons with neurobiotin and costaining for $\mathrm{TH}$ (Fig. 3D,E). We found that NEX-Cre ${ }^{+}$DA neurons had a distinct electrophysiological signature compared to "classic" SNc DA neurons. Specifically, NEX-Cre ${ }^{+}$DA neurons exhibited a more depolarized membrane potential $(\mathrm{Vm}$, $p=0.0075,{ }^{\mathrm{p}}$ unpaired $t$ test), had higher membrane resistance (Rm, $p<0.0001,{ }^{9}$ unpaired $t$ test), and reduced membrane capacitance $\left(\mathrm{Cm}, p<0.0001,{ }^{\mathrm{r}}\right.$ unpaired $t$ test $)$ compared to SNc DA neurons (Fig. $3 F-H$ ). The action potential height of NEX-Cre ${ }^{+}$DA neurons was also significantly shorter ( $p<0.0001,{ }^{\text {s }}$ unpaired $t$ test), and they had a less pronounced afterhyperpolarization (AHP, $p=$ $0.0002,{ }^{t}$ unpaired $t$ test; Fig. $\left.3 /-K\right)$. Due to their high membrane resistance, NEX-Cre ${ }^{+}$DA neurons required less negative current to hyperpolarize to $-100 \mathrm{mV}$ compared to SNc DA neurons (-25 to -50 pA for NEX-Cre ${ }^{+}$ neurons versus $-150 \mathrm{pA}$ for SNc neurons). NEX-Cre ${ }^{+} \mathrm{DA}$ neurons had a significantly smaller sag component, which is indicative of smaller $\mathrm{I}_{\mathrm{h}}\left(p<0.0001,{ }^{\mathrm{u}}\right.$ unpaired $t$ test, Fig. $3 L-N)$ and less rebound depolarization $\left(p<0.0001,{ }^{v}\right.$ unpaired $t$ test, Fig. $3 L, M, O)$. The noncanonical electrophysiological characteristics of $\mathrm{NEX}-\mathrm{Cre}^{+}$neurons are consistent with those reported for NAc medial shellprojecting DA neurons (Lammel et al., 2008), suggesting that Neurod6 is a useful marker for this VTA subpopulation.

\section{Neurod6-lacking VTA DA neurons show increased susceptibility to degeneration in a 6-OHDA mouse model}

In addition to their anatomic location, projection targets, and physiology, vulnerability to degeneration is a key feature of DA neurons that differs by subtype. Previous in vitro studies have implicated both Neurod6 and Grp as being potentially neuroprotective (Chung et al., 2005; Uittenbogaard and Chiaramello, 2005; Uittenbogaard et al., 2010; Baxter et al., 2012). In mice, expression of Neurod6 and the related transcription factor Neurod 1 are important for survival of DA neurons during development (Khan et al., 2017). Grp-expressing cells have been observed in postmortem tissue from PD patients, suggesting that Grp expression may be related to cell survival (Viereckel et al., 2016). We therefore investigated the sensitivity of $\mathrm{Neu}$ rod6 and/or Grp-expressing VTA DA neurons to degeneration in a mouse model of PD. To do this, we injected the dopaminergic toxin 6-hydroxydopamine (6-OHDA) unilaterally into the medial forebrain bundle of adult (P120) 

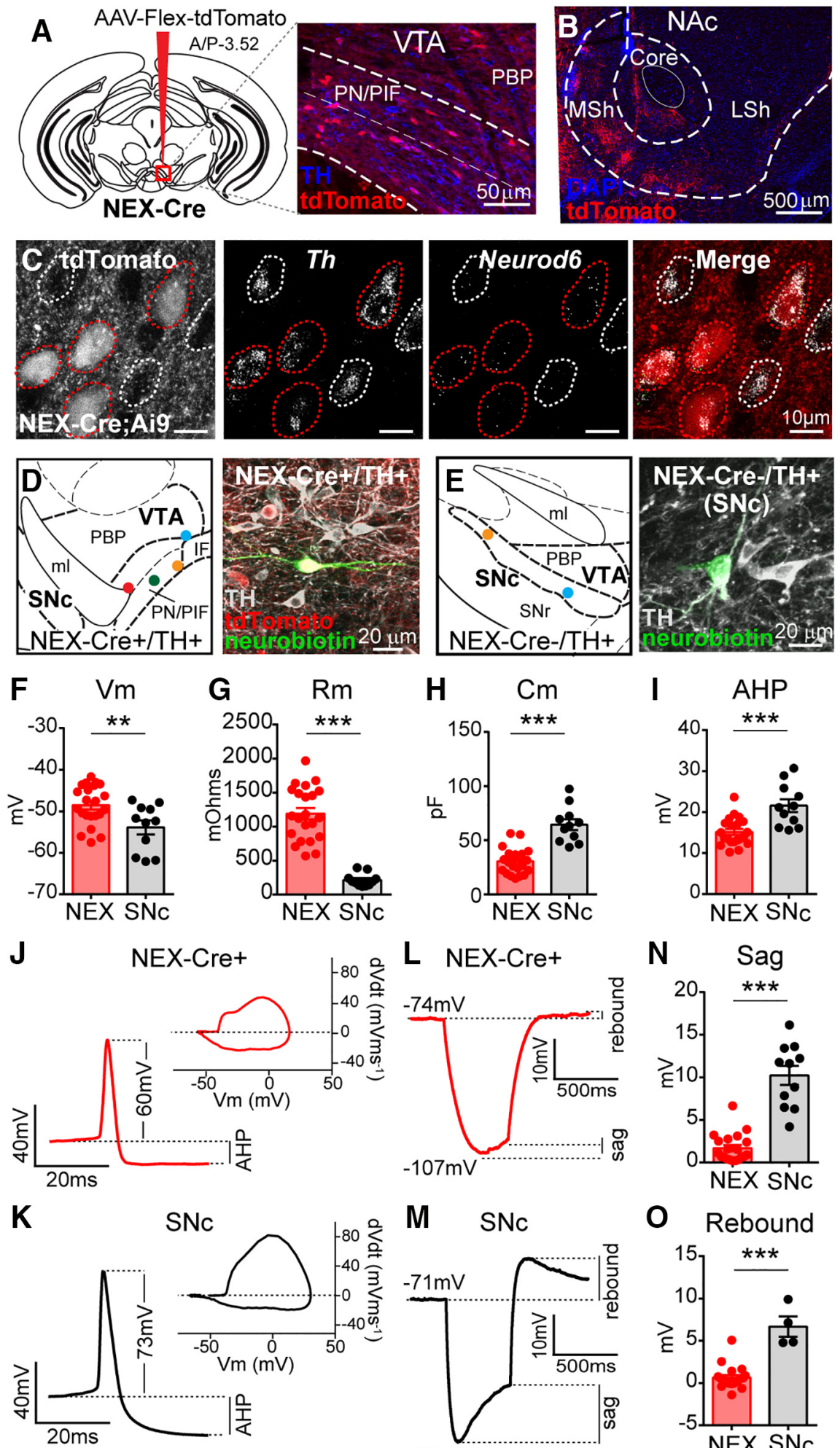

$M$
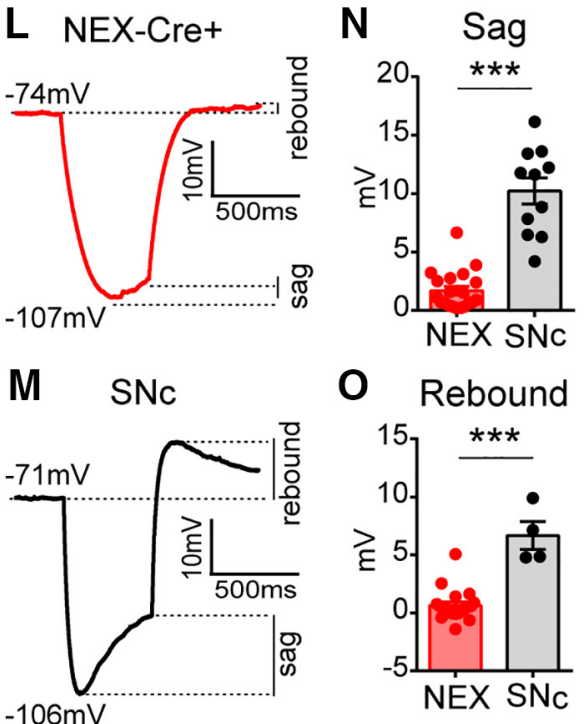

Figure 3. Neurod6-expressing DA neurons have noncanonical physiological properties. $\boldsymbol{A}$, Cre-dependent tdTomato-expressing virus (AAV-Flex-tdTomato) was injected unilaterally into the VTA of a NEX-Cre mouse. Right panel shows tdTomato-labeled NEX-Cre ${ }^{+}$ neurons in the ventromedial VTA. Tyrosine hydroxylase (TH) staining is in blue. $\boldsymbol{B}$, Confocal image of the nucleus accumbens (NAc) showing tdTomato-labeled projections from midbrain NEX-Cre ${ }^{+}$neurons. MSh, medial shell; LSh, lateral shell. $\boldsymbol{C}$, Confocal images of VTA neurons from NEX-Cre;Ai9 mice with fluorescent in situ hybridization (FISH) for tyrosine hydroxylase (Th) and Neurod6 mRNA. The tdTomato Cre-reporter is expressed in NEX-Cre ${ }^{+}$neurons. NEX-Cre ${ }^{+} / \mathrm{Neurod}^{+}$DA neurons are circled in red, NEX-Cre-/ Neurod $6^{+}$DA neurons are circled in white. $\boldsymbol{D}, \boldsymbol{E}$, Left panels show representative recording sites of NEX-Cre ${ }^{+}$VTA $(\boldsymbol{D})$ and NEX-CreSNc neurons $(\boldsymbol{E})$. Circles show the locations of recorded DA neurons. Right panels show examples of recorded, neurobiotin-filled 
continued

neurons positive for TH. $\boldsymbol{F}-\boldsymbol{I}$, Graphs display the mean \pm SEM membrane potential $(\boldsymbol{F}, \mathrm{Vm}, * *, p=0.0075)$, membrane resistance $(\boldsymbol{G}$, $\mathrm{Rm}, * * *, p<0.0001)$, capacitance $(\boldsymbol{H}, \mathrm{Cm}, * * *, p<0.0001)$, and afterhyperpolarization $(\boldsymbol{I}, \mathrm{AHP}, * * *, p=0.0002)$ for NEX-Cre ${ }^{+}$and SNc neurons. $\boldsymbol{J}, \boldsymbol{K}$, Representative action potential traces and phase plots $\left(\mathrm{mVms}^{-1} / \mathrm{mV}\right)$ from a NEX-Cre ${ }^{+}(\boldsymbol{J})$ and $S N c(\boldsymbol{K})$ neuron. $\boldsymbol{L}, \boldsymbol{M}$, Representative responses to a $500 \mathrm{~ms}$ negative current step from a NEX-Cre ${ }^{+}(-25 \mathrm{pA}, \boldsymbol{L})$ and $\mathrm{SNc}(-150 \mathrm{pA}, \boldsymbol{M})$ neuron. $\boldsymbol{N}$, Quantification of the mean \pm SEM sag component in NEX-Cre ${ }^{+}$and SNc neurons $(* * *, p<0.0001)$. O, Quantification of the mean \pm SEM rebound depolarization from neurons hyperpolarized to $-100 \pm 7 \mathrm{mV}$ (***, $p<0.0001)$. An unpaired $t$ test was used for all comparisons. For all panels, dots represent values from individual cells, NEX-Cre ${ }^{+} n=7$ male and 7 female mice, NEX-Cre-/SNc $n=$ 4 male mice and 1 female mouse. See Fig. 3-1 for a complete summary of the electrophysiology results.

female mice (Thiele et al., 2012). 6-OHDA resulted in a progressive, unilateral loss of DA neurons with a $96.0 \% \pm$ $0.6 \%$ reduction in SNc DA neurons and a $69.3 \pm 1.1 \%$ loss of VTA DA neurons after $4 \mathrm{wk}$ (Fig. 4A). We confirmed DA axon denervation throughout the striatum in the 6-OHDA-injected hemisphere, with notable sparing of DA projections to the NAc medial shell and core (Fig. 4B). DA neuron loss led to unilateral motor impairment as measured by the cylinder test $\left(p=0.0002,{ }^{w}\right.$ one-way ANOVA with Tukey's post hoc test: saline paw vs. 6-OHDA paw $p=0.0163$, saline paw vs. both paws $p=0.0157$, 6-OHDA paw vs. both paws $p=0.0002, n=4$ mice).

To determine how Grp- and Neurod6-expressing DA neurons in the VTA responded to 6-OHDA (Fig. 4C-F), we compared the reduction of $\mathrm{Grp}^{+}$and/or Neurod6 ${ }^{+}$VTA DA neurons between the saline and 6-OHDA hemisphere to all VTA DA neurons defined by Th expression (Fig. 4G). For this analysis, we included only VTA DA neurons, as essentially all SNc neurons (including $\mathrm{Grp}^{+} \mathrm{SNc}$ neurons) degenerated in the 6-OHDA-injected hemisphere (Fig. $4 A, C, D)$. We found that 4 wk following 6-OHDA injection, $26.1 \% \pm 2.7 \%$ of $\mathrm{Grp}^{+} /$Neurod $^{+}$DA neurons survived, which was similar to the percentage of total $\mathrm{Th}^{+}$VTA neurons surviving $\left(30.7 \% \pm 1.1 \% ; p<0.0001,{ }^{\mathrm{x}}\right.$ paired one-way ANOVA; $p=0.3169$, Tukey's post hoc test; Fig. $4 G)$. Notably, VTA DA neurons that expressed only Neurod6 and not Grp (Grp-/Neurod6 ${ }^{+}$) were significantly spared compared to the rest of VTA DA neurons, with $82.7 \% \pm 4.2 \%$ of neurons surviving $(p=0.0022$, Tukey's post hoc test, Fig. 4G). By contrast, VTA DA neurons that expressed Grp but not Neurod6 (Grp ${ }^{+} /$Neurod6 $^{-}$) showed slightly increased vulnerability compared to all VTA DA neurons, with $21.7 \% \pm 2.0 \%$ surviving $(p=0.0246$, Tukey's post hoc test, Fig. 4G). Therefore, the DA neuron subpopulations marked by expression of Grp and/or Neurod6 have different responses to 6-OHDA, and VTA neurons lacking Neurod6 are more susceptible to degeneration.

An increase in the proportion of Neurod $6^{+}$DA neurons in the VTA following 6-OHDA could be due to selective sparing of the Neurod6 cell population or from Neurod6 expression turning on in surviving neurons of other VTA subpopulations. To attempt to distinguish these possibilities, we performed FISH for another VTA DA neuron subtype marker Lypd1 (La Manno et al., 2016).

Under normal conditions, Lypd1 was expressed almost exclusively in the PBP subregion of the VTA as well as throughout the SNc (Fig. 4D,F). Neurod6 was generally not coexpressed in Lypd $1^{+}$DA neurons $(7.0 \% \pm 1.6 \%$ of Lypd1 ${ }^{+}$DA neurons coexpressed Neurod6, Fig. 4D,F,H), indicating that these markers define distinct cell popula- tions. In response to 6-OHDA, we found that $20.4 \% \pm$ $1.3 \%$ of $L y p d 1^{+} /$Neurod6- VTA DA neurons survived, which was significantly lower than the total VTA DA population ( $p=0.0403$, Tukey's post hoc test, Fig. 4G). The surviving Lypd $1^{+}$VTA DA neurons did not turn on expression of Neurod6, as the proportion of Neurod $6^{+} /$Lypd $^{+}$ VTA DA neurons remained low and was the same between the saline-injected and 6-OHDA-injected hemispheres $\left(p=0.8091,{ }^{y}\right.$ paired $t$ test, Fig. $\left.4 H\right)$. These results suggest that the VTA DA subpopulation defined by Neurod6 expression, which lacks Grp or Lypd1, is preferentially spared in response to a neurotoxic challenge.

\section{Discussion}

Midbrain DA neurons are small in number but vast in their behavioral influence (Björklund and Dunnett, 2007; Roeper, 2013). As such, dopaminergic dysfunction is associated with numerous psychiatric and neurologic disorders ranging from drug addiction to PD (Damier et al., 1999; Alberico et al., 2015; Nutt et al., 2015). Recent studies have revealed that the dopaminergic system is heterogeneous at multiple levels from gene expression to circuitry to physiology to behavior (Roeper, 2013; Morales and Margolis, 2017). To tackle this heterogeneity, genetic markers that define functional DA neuron subtypes are needed. This would enable the generation of tools that allow selective manipulation of dopaminergic subpopulations. Here, we investigated two markers that we and others have identified as labeling dopaminergic subpopulations, Grp and Neurod6. We show that the combinatorial expression of these genes defines the anatomic location, projection target, physiology, and disease susceptibility of DA neurons.

We found that Grp, which encodes the neuropeptide gastrin-releasing peptide (Roesler and Schwartsmann, 2012), was expressed in a third of midbrain DA neurons, of which more than half coexpressed Neurod6. These $\mathrm{Grp}^{+} / \mathrm{Neurod}^{+}$neurons resided in the VTA and projected to the medial portions of the NAc. This is consistent with prior reports showing that Grp is expressed in a subpopulation of VTA DA neurons that shows overlap with Neurod6-expressing neurons (Chung et al., 2005; Greene et al., 2005; Poulin et al., 2014; La Manno et al., 2016; Viereckel et al., 2016). The fact that these neurons project to the NAc corroborates a projection-specific translational profiling study reporting that ribosome-bound Grp mRNA was enriched in the population of VTA DA neurons projecting to the NAc (Ekstrand et al., 2014). Notably, we also identified a previously undiscovered population of Grp ${ }^{+}$ DA neurons that lack Neurod6, which were located in the 

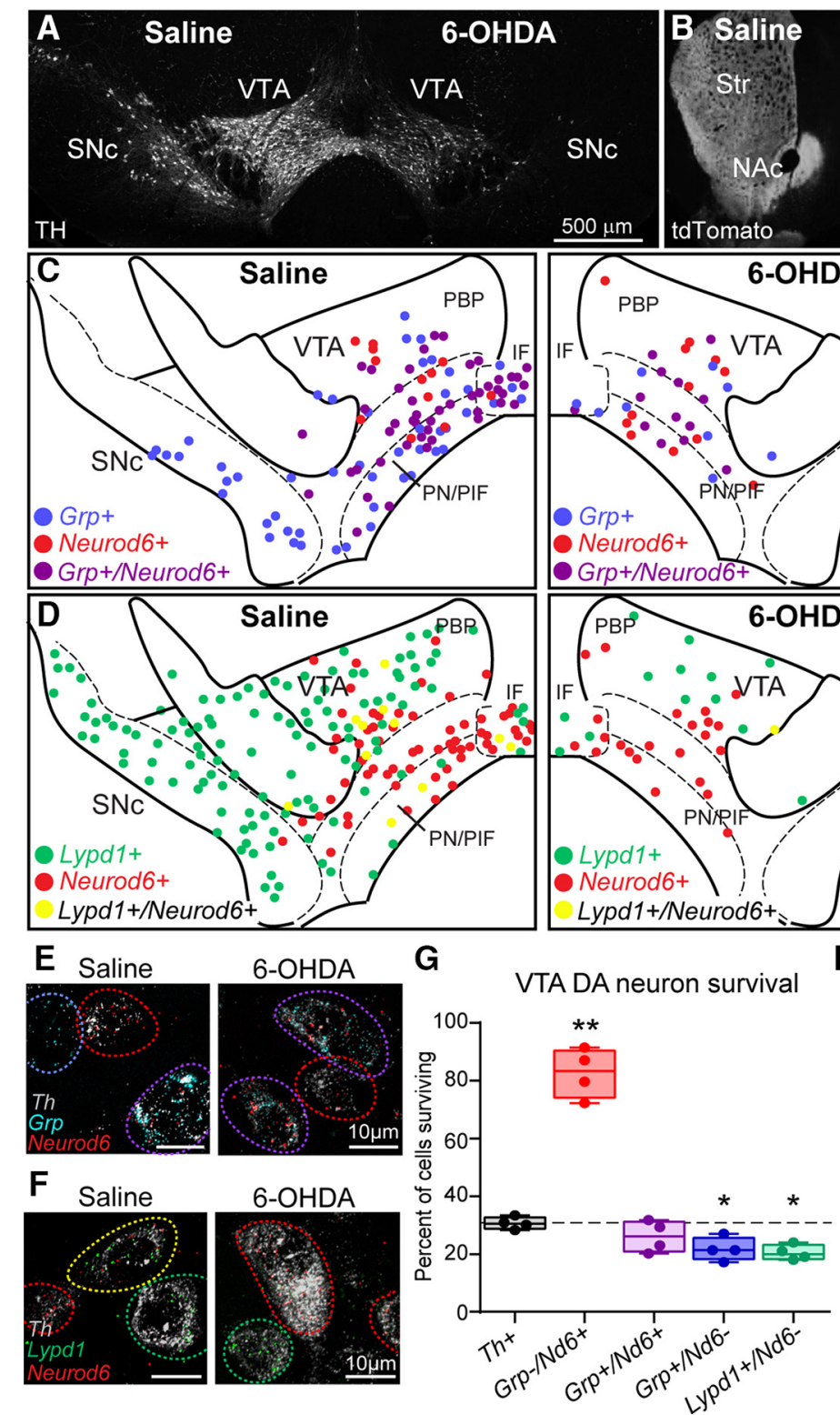

H $L y d p 1+/ N d 6+$
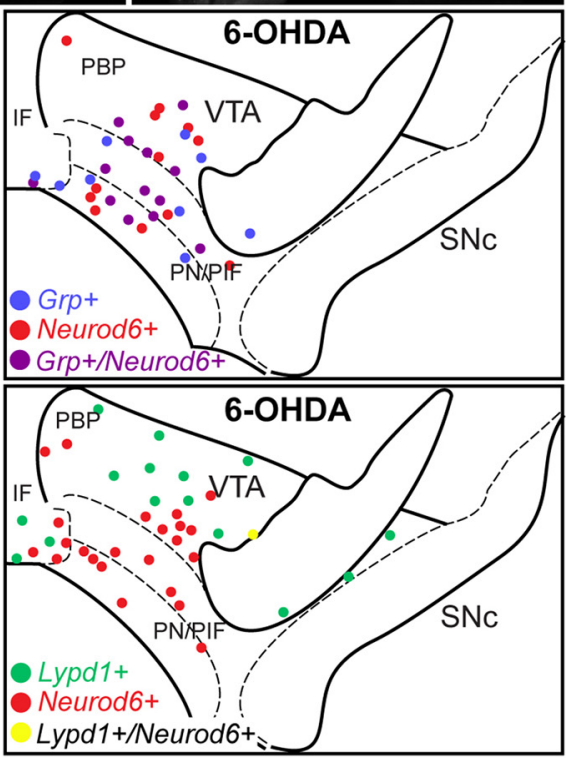

VTA DA neurons

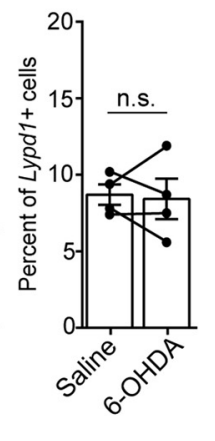

Figure 4. Neurod6-expression affects susceptibility to 6-OHDA-induced degeneration. $\boldsymbol{A}$, Confocal image of a midbrain section stained with a tyrosine hydroxylase $(\mathrm{TH})$ antibody $4 \mathrm{wk}$ after unilateral saline (left) or 6-OHDA (right) injection into the medial forebrain bundle. $\boldsymbol{B}$, Image of a striatal (Str) section showing loss of tdTomato ${ }^{+}$axon terminals 4 wk following unilateral 6-OHDA injection in a DAT ${ }^{I R E S}$ Cre;Ai9 mouse. NAc, nucleus accumbens. C, Schematic showing the location of DA neurons in the saline and 6-OHDA injected hemispheres labeled with different markers by fluorescent in situ hybridization (FISH): blue circles are Grp ${ }^{+}$, red circles are Neurod $6^{+}$, and purple circles are $\mathrm{Grp}^{+} / \mathrm{Neurod}^{+}$. D. Schematic showing the location of Lypd $1^{+}$(green), Neurod6 ${ }^{+}$(red), and Lypd $1^{+} /$Neurod $^{+}$(yellow) DA neurons in the midbrain following saline and 6-OHDA injection. $\boldsymbol{E}$, $\boldsymbol{F}$, Confocal images of FISH for the indicated markers. E, Images show Grp ${ }^{+}$(blue circle), Neurod6 ${ }^{+}$(red circles), and Grp ${ }^{+} /$Neurod6 $^{+}$(purple circles) DA neurons in the VTA following saline and 6-OHDA injection. $\boldsymbol{F}$, Images show Lypd1 $1^{+}$(green circles), Neurod6 ${ }^{+}$(red circles), and Lypd1 ${ }^{+} / \mathrm{Neurod}^{+}$ (yellow circle) DA neurons in the VTA following saline and 6-OHDA injection. G, Box-and-whisker plots (min to max) show the percentage of VTA DAT neurons expressing each set of markers in the 6-OHDA-injected hemisphere compared to the saline-injected hemisphere. Dotted line represents the percentage of all VTA DA neurons $\left(\mathrm{Th}^{+}\right)$surviving in the 6-OHDA hemisphere. Dots represent data from individual mice, $n=4$ female mice. A paired one-way ANOVA with Dunnett's multiple comparisons test was used to compare each subpopulation to all Th ${ }^{+}$VTA DA neurons $\left(n=4376\right.$ saline and 13526 -OHDA cells): Grp $/ \mathrm{Neurod}^{+}(n=184$ saline and 1516 -OHDA cells), $* * p=0.0022 ;$ Grp $^{+} /$Neurod6 $^{+}\left(n=763\right.$ saline and 2076 -OHDA cells), $p=0.3169 ;$ Grp $^{+} /$Neurod6 $^{-}(n=749$ saline and 1656 -OHDA cells), $* p=0.0246 ;$ Lypd1 $^{+} /$Neurod6 $^{-}(n=1056$ saline and 1716 -OHDA cells), $* p=0.0313 ;$ Nd6 $=$ Neurod6. $\boldsymbol{H}$, Bar graphs display the percentage of $L y p d 1^{+}$VTA DA neurons that coexpress Neurod6 mRNA in the saline-injected $(n=$ $102 / 3750$ cells) and 6-OHDA-injected ( $n=16 / 904$ cells) hemispheres. Bars represent mean \pm SEM, dots represent the values from individual mice, $n=4$ female mice; paired $t$ test, n.s., not significant, $p=0.8091$. 
ventromedial portion of the SNc. These neurons sent projections to the DMS with very little innervation of the DLS. The anatomic location of these cells in the ventral $\mathrm{SNc}$ is consistent with DA neurons that project to the DMS, which have unique physiological and behavioral properties compared to DLS-projecting DA neurons located in the dorsal SNc (Lerner et al., 2015).

Neurod6 expression defined a smaller population of DA neurons that were located in the ventromedial VTA, projected selectively to the NAc, and exhibited noncanonical physiologic properties. While Neurod6 has previously been identified as a VTA marker (Chung et al., 2005; La Manno et al., 2016; Viereckel et al., 2016; Khan et al., 2017), our study is the first to systematically map the projection sites of these cells, revealing a strong medial shell NAc projection with very little output to other DA target regions. This medial shell NAc projection is consistent with the physiology of Neurod6 $6^{+}$DA neurons, which showed unique characteristics similar to those previously reported for medial NAc-projecting DA neurons defined by retrograde labeling (Lammel et al., 2008). Mesoaccumbens projections are important for mediating reward-seeking behaviors (Yun et al., 2004; Ikemoto, 2007; Lammel et al., 2011, 2014). Therefore, our identification of Neurod6 as a marker for this cell population enables future mechanistic investigations into how this DA subcircuit controls motivated behaviors, the dysfunction of which may be important for the pathophysiology of psychiatric disorders such as drug addiction.

It was previously reported that $\mathrm{Neurod}^{+}{ }^{+}$neurons project to the lateral septum based on the axon projections of NEX-Cre mice and fluorogold retrograde labeling (Khan et al., 2017). However, projections from the VTA to the lateral septum are relatively sparse compared to the striatum and NAc (Beckstead et al., 1979; Swanson, 1982; Beier et al., 2015). To investigate this further, we performed retrobead injections into the dorsal and intermediate regions of the lateral septum and found that relatively few VTA DA neurons projected to this area. The lateral septum therefore represented only $2 \%$ of total bead-labeled Neurod $6^{+}$DA cells across all injection sites. This indicates that under our conditions, the lateral septum was not a primary projection site of Neurod $^{+}$DA neurons. One possible reason for the discrepancy is that the Khan et al. (2017) study relied exclusively on the NEX-Cre mouse line, as opposed to endogenous $\mathrm{Neu}$ rod6 expression as done here. We found that a substantial proportion $(37 \%)$ of the VTA neurons labeled in NEXCre mice are non-dopaminergic and that many of the VTA neurons projecting to the lateral septum are also nondopaminergic $(37 \%)$, which may have contributed to the differing results.

A defining feature of DA neurons is their susceptibility or resilience to degeneration in the context of PD (Damier et al., 1999; Alberico et al., 2015). As such, significant effort has been made to identify the molecules that determine vulnerability, as this has clear clinical importance (Brichta and Greengard, 2014). Interestingly, in addition to being genes that define specific DA neuron subtypes, both Neurod6 and Grp have been shown to confer neu- roprotection in cell culture models (Chung et al., 2005; Uittenbogaard and Chiaramello, 2005; Uittenbogaard et al., 2010; Baxter et al., 2012). To determine if the neuronal populations defined by Neurod6 and/or Grp are preferentially spared in the context of PD, we performed unilateral $6-\mathrm{OHDA}$ injections and compared the relative abundance of these markers in the 6-OHDA versus control hemisphere. We found that expression of either of these genes alone was not sufficient to confer neuroprotection, as $\mathrm{Grp}^{+}$neurons in the SNc degenerated completely and $\mathrm{Grp}^{+}$neurons in the VTA showed either similar $\left(\mathrm{Grp}^{+} /\right.$ Neurod $6^{+}$) or greater (Grp ${ }^{+} /$Neurod6-) susceptibility relative to all VTA DA neurons. Notably, we did find that the small population of Neurod6 ${ }^{+}$VTA DA neurons that lack Grp was significantly spared compared to neighboring DA neurons. This finding is consistent with a potential neuroprotective effect of Neurod 6 but indicates that other factors are likely involved, since Neurod $6^{+}$VTA DA neurons that coexpressed Grp were not preferentially spared. Together, these results refine our understanding of the genetic factors contributing to vulnerable and spared DA cell types and suggest that the combinatorial expression of genes in a given cell population is important for defining vulnerability.

In summary, our work provides in-depth characterization of Neurod6 and Grp expression in the midbrain and reveals previously unappreciated complexity in how these markers define specific DA subpopulations. Our results provide new insights into the genetic and functional heterogeneity of the DA system, which is just beginning to be unraveled. Future studies can use this information to design intersectional genetic tools based on the expression of two or more genes that will allow access to specific dopaminergic subpopulations. These types of tools represent powerful approaches to dissecting the complex ways in which the DA system contributes to behavior and disease.

\section{References}

Alberico SL, Cassell MD, Narayanan NS (2015) The vulnerable ventral tegmental area in Parkinson's disease. Basal Ganglia 5:51-55. CrossRef Medline

Bäckman CM, Malik N, Zhang Y, Shan L, Grinberg A, Hoffer BJ, Westphal H, Tomac AC (2006) Characterization of a mouse strain expressing Cre recombinase from the 3 ' untranslated region of the dopamine transporter locus. Genesis 44:383-390. CrossRef

Bateup HS, Johnson CA, Denefrio CL, Saulnier JL, Kornacker K, Sabatini BL (2013) Excitatory/inhibitory synaptic imbalance leads to hippocampal hyperexcitability in mouse models of tuberous sclerosis. Neuron 78:510-522. CrossRef

Baxter KK, Uittenbogaard M, Chiaramello A (2012) The neurogenic basic helix-loop-helix transcription factor NeuroD6 enhances mitochondrial biogenesis and bioenergetics to confer tolerance of neuronal PC12-NeuroD6 cells to the mitochondrial stressor rotenone. Exp Cell Res 318:2200-2214. CrossRef

Beckstead RM, Domesick VB, Nauta WJ (1979) Efferent connections of the substantia nigra and ventral tegmental area in the rat. Brain Res 175:191-217. Medline

Beier KT, Steinberg EE, DeLoach KE, Xie S, Miyamichi K, Schwarz L, Gao XJ, Kremer EJ, Malenka RC, Luo L (2015) Circuit architecture of VTA dopamine neurons revealed by systematic input-output mapping. Cell 162:622-634. CrossRef 
Björklund A, Dunnett SB (2007) Dopamine neuron systems in the brain: an update. Trends Neurosci 30:194-202. CrossRef Medline

Blesa J, Przedborski S (2014) Parkinson's disease: animal models and dopaminergic cell vulnerability. Front Neuroanat 8:155. CrossRef Medline

Bolger AM, Lohse M, Usadel B (2014) Trimmomatic: a flexible trimmer for Illumina sequence data. Bioinformatics 30:2114-2120. CrossRef Medline

Bolstad BM, Irizarry RA, Astrand M, Speed TP (2003) A comparison of normalization methods for high density oligonucleotide array data based on variance and bias. Bioinformatics 19:185-193. CrossRef

Brichta L, Greengard P (2014) Molecular determinants of selective dopaminergic vulnerability in Parkinson's disease: an update. Front Neuroanat 8:152. CrossRef

Bullard JH, Purdom E, Hansen KD, Dudoit S (2010) Evaluation of statistical methods for normalization and differential expression in mRNA-Seq experiments. BMC Bioinformat 11:94. CrossRef Medline

Chan CS, Guzman JN, Ilijic E, Mercer JN, Rick C, Tkatch T, Meredith GE, Surmeier DJ (2007) 'Rejuvenation' protects neurons in mouse models of Parkinson's disease. Nature 447:1081-1086. CrossRef Medline

Chung CY, Seo H, Sonntag KC, Brooks A, Lin L, Isacson O (2005) Cell type-specific gene expression of midbrain dopaminergic neurons reveals molecules involved in their vulnerability and protection. Hum Mol Genet 14:1709-1725. CrossRef

Cole MB, Risso D, Wagner A, DeTomaso D, Ngai J, Purdom E, Dudoit S, Yosef N (2017) Performance assessment and selection of normalization procedures for single-cell RNA-Seq. bioRxiv doi: 10.1101/235382.

Damier P, Hirsch EC, Agid Y, Graybiel AM (1999) The substantia nigra of the human brain. II. Patterns of loss of dopaminecontaining neurons in Parkinson's disease. Brain 122:14371448. CrossRef

Di Salvio M, Di Giovannantonio LG, Acampora D, Prosperi R, Omodei D, Prakash N, Wurst W, Simeone A (2010a) Otx2 controls neuron subtype identity in ventral tegmental area and antagonizes vulnerability to MPTP. Nat Neurosci 13:1481-1488. CrossRef

Di Salvio M, Di Giovannantonio LG, Omodei D, Acampora D, Simeone $A(2010 b)$ Otx2 expression is restricted to dopaminergic neurons of the ventral tegmental area in the adult brain. Int $\mathrm{J}$ Dev Biol 54:939-945. CrossRef Medline

Ekstrand MI, Nectow AR, Knight ZA, Latcha KN, Pomeranz LE, Friedman JM (2014) Molecular profiling of neurons based on connectivity. Cell 157:1230-1242. CrossRef Medline

Fletcher RB, Das D, Gadye L, Street KN, Baudhuin A, Wagner A, Cole MB, Flores Q, Choi YG, Yosef N, et al. (2017) Deconstructing olfactory stem cell trajectories at single-cell resolution. Cell Stem Cell 20:817-830.e818. CrossRef Medline

Goebbels S, Bormuth I, Bode U, Hermanson O, Schwab MH, Nave KA (2006) Genetic targeting of principal neurons in neocortex and hippocampus of NEX-Cre mice. Genesis 44:611-621. CrossRef Medline

Greene JG, Dingledine R, Greenamyre JT (2005) Gene expression profiling of rat midbrain dopamine neurons: implications for selective vulnerability in parkinsonism. Neurobiol Dis 18:19-31. CrossRef

Grimm J, Mueller A, Hefti F, Rosenthal A (2004) Molecular basis for catecholaminergic neuron diversity. Proc Natl Acad Sci U S A 101:13891-13896. CrossRef

Ikemoto S (2007) Dopamine reward circuitry: two projection systems from the ventral midbrain to the nucleus accumbens-olfactory tubercle complex. Brain Res Rev 56:27-78. CrossRef

Khan S, Stott SR, Chabrat A, Truckenbrodt AM, Spencer-Dene B, Nave KA, Guillemot F, Levesque M, Ang SL (2017) Survival of a novel subset of midbrain dopaminergic neurons projecting to the lateral septum is dependent on neuroD proteins. J Neurosci 37: 2305-2316. CrossRef
Kim D, Pertea G, Trapnell C, Pimentel H, Kelley R, Salzberg SL (2013) TopHat2: accurate alignment of transcriptomes in the presence of insertions, deletions and gene fusions. Genome Biol 14:R36. CrossRef Medline

La Manno G, Gyllborg D, Codeluppi S, Nishimura K, Salto C, Zeisel A, Borm LE, Stott SRW, Toledo EM, Villaescusa JC, et al . (2016) Molecular diversity of midbrain development in mouse, human, and stem cells. Cell 167:566-580.e519. CrossRef Medline

Lammel S, Hetzel A, Hackel O, Jones I, Liss B, Roeper J (2008) Unique properties of mesoprefrontal neurons within a dual mesocorticolimbic dopamine system. Neuron 57:760-773. CrossRef

Lammel S, Ion DI, Roeper J, Malenka RC (2011) Projection-specific modulation of dopamine neuron synapses by aversive and rewarding stimuli. Neuron 70:855-862. CrossRef

Lammel S, Lim BK, Malenka RC (2014) Reward and aversion in a heterogeneous midbrain dopamine system. Neuropharmacology 76:351-359. CrossRef Medline

Lammel S, Lim BK, Ran C, Huang KW, Betley MJ, Tye KM, Deisseroth K, Malenka RC (2012) Input-specific control of reward and aversion in the ventral tegmental area. Nature 491:212-217. CrossRef Medline

Law CW, Chen Y, Shi W, Smyth GK (2014) Voom: Precision weights unlock linear model analysis tools for RNA-seq read counts. Genome Biol 15:R29. CrossRef Medline

Lerner TN, Shilyansky C, Davidson TJ, Evans KE, Beier KT, Zalocusky KA, Crow AK, Malenka RC, Luo L, Tomer R, et al . (2015) Intact-brain analyses reveal distinct information carried by $\mathrm{SNc}$ dopamine subcircuits. Cell 162:635-647. CrossRef

Liao Y, Smyth GK, Shi W (2014) featureCounts: an efficient general purpose program for assigning sequence reads to genomic features. Bioinformatics 30:923-930. CrossRef

Liss B, Haeckel O, Wildmann J, Miki T, Seino S, Roeper J (2005) K-ATP channels promote the differential degeneration of dopaminergic midbrain neurons. Nat Neurosci 8:1742-1751. CrossRef

Liu G, Yu J, Ding J, Xie C, Sun L, Rudenko I, Zheng W, Sastry N, Luo J, Rudow G, et al. (2014) Aldehyde dehydrogenase 1 defines and protects a nigrostriatal dopaminergic neuron subpopulation. J Clin Invest 124:3032-3046. CrossRef

Madisen L, Zwingman TA, Sunkin SM, On SW, Zariwala HA, Gu H, Ng LL, Palmiter RD, Hawrylycz MJ, Jones AR, et al . (2010) A robust and high-throughput Cre reporting and characterization system for the whole mouse brain. Nat Neurosci 13:133-140. CrossRef

Margolis EB, Mitchell JM, Ishikawa J, Hjelmstad GO, Fields HL (2008) Midbrain dopamine neurons: projection target determines action potential duration and dopamine $D(2)$ receptor inhibition. $J$ Neurosci 28:8908-8913. CrossRef

Menegas W, Bergan JF, Ogawa SK, Isogai Y, Umadevi Venkataraju K, Osten P, Uchida N, Watabe-Uchida M (2015) Dopamine neurons projecting to the posterior striatum form an anatomically distinct subclass. eLife 4:e10032. CrossRef

Morales M, Margolis EB (2017) Ventral tegmental area: cellular heterogeneity, connectivity and behaviour. Nat Rev Neurosci 18:7385. CrossRef Medline

Nutt DJ, Lingford-Hughes A, Erritzoe D, Stokes PR (2015) The dopamine theory of addiction: 40 years of highs and lows. Nat Rev Neurosci 16:305-312. CrossRef

Poulin JF, Tasic B, Hjerling-Leffler J, Trimarchi JM, Awatramani R (2016) Disentangling neural cell diversity using single-cell transcriptomics. Nat Neurosci 19:1131-1141. CrossRef

Poulin JF, Zou J, Drouin-Ouellet J, Kim KY, Cicchetti F, Awatramani RB (2014) Defining midbrain dopaminergic neuron diversity by single-cell gene expression profiling. Cell Rep 9:930-943. CrossRef

Risso D, Perraudeau F, Gribkova S, Dudoit S, Vert JP (2018a) A general and flexible method for signal extraction from single-cell RNA-seq data. Nat Commun 9:284. CrossRef Medline

Risso D, Purvis L, Fletcher R, Das D, Ngai J, Dudoit S, Purdom E (2018b) clusterExperiment and RSEC: a Bioconductor package 
and framework for clustering of singlecell and other large gene expression datasets. bioRxiv doi: 10.1101/280545.

Roeper J (2013) Dissecting the diversity of midbrain dopamine neurons. Trends Neurosci 36:336-342. CrossRef Medline

Roesler R, Schwartsmann G (2012) Gastrin-releasing peptide receptors in the central nervous system: role in brain function and as a drug target. Front Endocrinol 3:159. CrossRef

Romanov RA, Zeisel A, Bakker J, Girach F, Hellysaz A, Tomer R, Alpár A, Mulder J, Clotman F, Keimpema E, et al . (2017) Molecular interrogation of hypothalamic organization reveals distinct dopamine neuronal subtypes. Nat Neurosci 20:176-188. CrossRef

Swanson LW (1982) The projections of the ventral tegmental area and adjacent regions: a combined fluorescent retrograde tracer and immunofluorescence study in the rat. Brain Res Bull 9:321353. CrossRef

Thiele SL, Warre R, Nash JE (2012) Development of a unilaterallylesioned 6-OHDA mouse model of Parkinson's disease. J Vis Exp 60:pii3234. CrossRef Medline

Uittenbogaard M, Baxter KK, Chiaramello A (2010) The neurogenic basic helix-loop-helix transcription factor NeuroD6 confers tolerance to oxidative stress by triggering an antioxidant response and sustaining the mitochondrial biomass. ASN Neuro 2:e00034. CrossRef
Uittenbogaard M, Chiaramello A (2005) The basic helix-loop-helix transcription factor Nex-1/Math-2 promotes neuronal survival of PC12 cells by modulating the dynamic expression of anti-apoptotic and cell cycle regulators. J Neurochem 92:585-596. CrossRef

van der Maaten L, Hinton G (2008) Visualizing data using t-SNE. J Mach Learn Res 9:2579-2605.

Viereckel T, Dumas S, Smith-Anttila CJ, Vlcek B, Bimpisidis Z, Lagerström MC, Konradsson-Geuken A, Wallén-Mackenzie A (2016) Midbrain gene screening identifies a new mesoaccumbal glutamatergic pathway and a marker for dopamine cells neuroprotected in Parkinson's disease. Sci Rep 6:35203. CrossRef

Vogt Weisenhorn DM, Giesert F, Wurst W (2016) Diversity matters: heterogeneity of dopaminergic neurons in the ventral mesencephalon and its relation to Parkinson's disease. J Neurochem 139:826. CrossRef

Watabe-Uchida M, Zhu L, Ogawa SK, Vamanrao A, Uchida N (2012) Whole-brain mapping of direct inputs to midbrain dopamine neurons. Neuron 74:858-873.

Yun IA, Wakabayashi KT, Fields HL, Nicola SM (2004) The ventral tegmental area is required for the behavioral and nucleus accumbens neuronal firing responses to incentive cues. J Neurosci 24: 2923-2933. CrossRef Medline 